\title{
Field testing of a novel hybrid solar assisted desiccant evaporative cooling system coupled with a vapour compression heat pump
}

\author{
A. Frein *, M. Muscherà, R. Scoccia, M. Aprile, M. Motta \\ Department of Energy, Politecnico di Milano, 20156 Milano, Italy
}

\section{HIGHLIGHTS}

- The experimental operation of a solar driven hybrid DEC system is presented.

- In situ monitoring data are analysed and compared to the system's expected performance.

- Drawbacks affecting the system's performance are explained.

- Fine-tuning of the control and maintenance strategy of the main system components is suggested.

\begin{abstract}
The aim of this paper is to report on a two-year operational experience with a solar driven desiccant and evaporative cooling (SDEC) system coupled with a vapour compression heat pump. The main objectives are to analyse the benefits and drawbacks of this innovative hybrid SDEC system, to compare the mon-itoring results against the expected theoretical ones, and to assess the system's performance with respect to a reference air handling unit. The comparison focuses on the summer key operation modes using Primary Energy Ratio (PER) as indicator of the entire system performance. The results of the detailed analysis lead to the following conclusions: the specific design of the hybrid SDEC leads to high air quality, simpler control process and low electricity consumption for partial load conditions. The monitoring results show a summer mode PER 20\% lower than expected due to underperformance of the desiccant wheel. Nevertheless, this innovative system is still very efficient as its PER is twice as high as the one of the considered reference system. Lastly, suggestions for optimization of the existing system through the fine-tuning of the control strategy of its main components are presented.
\end{abstract}

\section{Introduction}

Reducing energy consumption and eliminating wastage are among the main goals of most of non-developing countries. Energy efficiency is decisive for competitiveness, security of supply and for meeting the commitments on climate change made under the Kyoto protocol. Buildings are responsible for roughly $40 \%$ of energy consumption and $36 \%$ of $\mathrm{CO} 2$ emissions in the EU, thus the EU has introduced legislation to ensure that they consume less energy. With the adoption of the recast EPBD in 2010 (Directive 2010/31/ EU), EU Member States faced new tough challenges. Among them, moving towards new and retrofitted nearly-zero energy buildings by 2020 (2018 in the case of Public buildings), and the application of a cost-optimal methodology for setting minimum requirements for both the envelope and the technical systems. The so-called DEC (Desiccant Evaporative Cooling) is an air-conditioning system based on the use of a desiccant process combined with an evaporative cooling process [1]. A desiccant process consists in the absorption or adsorption of water vapour by a substance, which can be natural or synthetic. The driving force is the water vapour pressure difference between the surroundings moist air and the desiccant surface. Desiccant materials are primarily classified according to their states, liquid or solid, at operating condition. Generally, liquid desiccants are characterized by flexibility and lower regeneration temperature and pressure drop on air side. On the other hand, solid desiccants are compact and do not involve corrosion issues. The most used desiccant materials are: lithium chloride, triethylene glycol, silica gels, aluminium silicates (zeolites or molecular sieves), aluminium oxides, lithium bromide solution and lithium chloride solution with water. Moreover, tailored desiccant substance can be engineered like ionic liquid. Desiccant

\footnotetext{
* Corresponding author.

E-mail address: antoine.frein@polimi.it (A. Frein).
} 


\section{Nomenclature}

\begin{tabular}{|c|c|c|c|}
\hline G & solar irradiation, $\mathrm{W} / \mathrm{m}^{2}$ & BUH & back-up heater \\
\hline$h$ & enthalpy, $\mathrm{kJ} \mathrm{kg}^{-1}$ & BUHE & back up heat exchanger \\
\hline$\dot{m}$ & mass flow rate, $\mathrm{kg} \mathrm{s}^{-1}$ & c.n. & case number \\
\hline$\dot{P}$ & electrical power, kW & COP & coefficient of performance (cooling mode) \\
\hline$\dot{Q}$ & heat transfer rate, $\mathrm{kW}$ & CV & control valve \\
\hline $\mathrm{RH}$ & relative humidity, - & $\mathrm{d}$ & day \\
\hline$T$ & temperature, ${ }^{\circ} \mathrm{C}$ & DEC & desiccant evaporative cooling \\
\hline$t$ & time, min & $\mathrm{DH}$ & dehumidification mode \\
\hline \multirow[t]{2}{*}{$x$} & humidity by mass in the moist air, $\mathrm{g}_{\mathrm{w}} \mathrm{kg}_{\mathrm{DA}}^{-1}$ & DW & desiccant wheel \\
\hline & & DV & diverter valve \\
\hline \multicolumn{2}{|c|}{ Greek symbols } & EA & External air (supply stream) \\
\hline$\Delta$ & difference & FC & free cooling mode \\
\hline \multirow{2}{*}{$\eta_{\mathbf{T}}$} & temperature efficiency & HP & heat pump \\
\hline & & $\mathrm{HR}$ & heat recovery mode \\
\hline \multicolumn{2}{|c|}{ Subscripts } & $\mathrm{hr}$ & yearly hour \\
\hline \multirow{2}{*}{$\begin{array}{l}D A \\
e\end{array}$} & dry air & HX & static air heat exchanger \\
\hline & electrical & HU & humidifier \\
\hline lat & latent & IEC & indirect evaporative cooling mode \\
\hline ref & reference system & $\mathrm{m}$ & month \\
\hline reg & DW regeneration & $\mathrm{OA}$ & Outside air (regeneration stream) \\
\hline$s$ & sensible & $\mathrm{P}$ & pump \\
\hline$a$ & air & PEF & primary energy factor \\
\hline$w$ & water & PER & primary energy ratio \\
\hline th & Water & PI & proportional-integral control \\
\hline ufl & thermal & RA & Return air \\
\hline ujl & & RPH & rotation per hour \\
\hline & & SA & Supply air \\
\hline Abbrevi & ions & SDEC & solar desiccant evaporative cooling \\
\hline AC & active cooling mode & SF & solar fraction \\
\hline $\mathrm{AH}$ & active heating mode & ST & solar thermal field \\
\hline AHU & air handling unit & VE & fan \\
\hline AS-HP & electrical air source heat pump & WW-HP & electrical water-water heat pump \\
\hline B & coils & $\mathrm{V}$ & year \\
\hline BLR & condensing gas boiler & $\mathrm{y}$ & \\
\hline $\mathrm{BP}$ & bypass & & \\
\hline
\end{tabular}

materials can be used in several technological arrangements. In the air-conditioning sector the most common use of desiccant materials is as coatings of rotating wheels, usually called desiccant wheels (or rotors). The desiccant wheel rotates slowly (order of magnitude $10 \mathrm{RPH}$ ) in a special containment structure and it is divided into two areas. The first area is used to adsorb the water vapour of process air, and the other is used to ensure a continu-ously operating cycle regenerating the rotor by removing the water uptake through an auxiliary hotter air flow (regeneration air). An issue of this arrangement is the carryover, which means that a transfer of air containing moisture or other contaminants from the regeneration to the process side of the wheel could occur, either by seal leakage or wheel rotation. In order to limit this effect, a purge section can be implemented, which acts as an extension of the exhaust air duct into the supply air duct. In the scientific liter-ature, many studies deal with the mathematical modelling of the complex physical phenomena that occur in a desiccant wheel $[2,3,4,5,6]$. In the last few years many research works have dealt with solid DEC cycle for air-conditioning $[1,7,8,9]$. The reason is that a DEC cycle could be activated by low temperature heat like waste heat and solar heat. Under this condition a DEC cycle could become competitive and cost effective. An example is reported by Henning [10], which has described a DEC system installed at the building of the chamber of trade and commerce in Freiburg/Ger-many, using solar air collector for the desiccant wheel regenera-tion. Starting from standard solid DEC cycle, several configurations have been investigated in the scientific literature.
The most common upgrades of the standard solid DEC cycle are:(a) increase the sensible cooling capacity of the system adding a postcooling coil at the end of the supply air duct; (b) increase the dehumidification capacity adding a cooling coil before the desiccant wheel on the supply air duct; (c) increase the dehumidification capacity adding a second desiccant wheel heating coil pair in series to the first one. As previously mentioned, a DEC cycle cannot be compared with a reference system without the specification of the heating and cooling coils energy sources. For example, Henning et al. [11] has proposed a tri-generation system based on a solid DEC cycle, a co-generation system and an electric chiller. Specifically, the co-generation system drives both the DEC cycle regeneration and an electric chiller that feeds two additional cooling coils in the DEC cycle (one for pre-dehumidification and one for postcooling). Another interesting configuration has been presented by Mazzei et al. [12] and further investigated by Beccali et al.[13,14] and Aprile et al. [15]. The basic concept is to use a solid DEC cycle with a post-cooling coil and a water-water chiller. As this configuration needs at the same time cooling power and heat-ing power, the chiller heat source is the supply air and the heat sink is the regeneration air. Due to the maximum temperature levels limitation of the electric heat pump, both Beccali and Aprile have used the chiller rejected heat only for a pre-heating phase of the regeneration air, adding a second heating system in series. Frein et al. [16] have defined and applied a continuous monitoring methodology on the system presented by Aprile et al. [15], including transition and partial load behaviour, in order to assess the 
energy performance of the single system components and identify possible faults throughout the system operating life. In this paper, the main experimental results of the hybrid solar DEC system theoretically analysed by Aprile et al. [15] are presented. Here the main goals are to present and optimize the whole system performance focusing on the summer key operation modes.

\section{Solar DEC system}

In this Section, a general description of the hybrid solar DEC system implemented in Milan and its expected performance under summer nominal conditions are presented

\subsection{Plant description and control strategy}

\subsubsection{End-user}

The system under analysis has been installed in 2013 at a dormitory for students in Milan in order to supply part of the primary air needed for the indoor air quality and for the balancing of the latent thermal load.

\subsubsection{Special request/ goals}

- High air quality: Due to odour contamination of the exhaust air, the air handling unit configuration had to prevent return air from mixing with supply air. Therefore, a flat plate sensible heat exchanger was selected instead of a rotary one and an additional stream of outdoor air was used for the desiccant wheel regeneration. A reversible water/water heat pump provides both heating in winter and sensible cooling in summer. The peculiarities of the plant lie in the following: (a) in summer, the heat pump cools the supply air and pre- heats the regeneration air, when dehumidification is needed; (b) in winter, the heat pump upgrades the solar heat to a higher level of temperature, if a minimum temperature is available in the heat storage, otherwise the hot backup is used.

- Low electricity consumption: by avoiding the pressure drop caused by additional rotary heat exchangers, the electricity consumption of the two bypass and regeneration channel fans was reduced;

- Simpler control scheme: replacing direct evaporative cooling systems with the cooling coil simplifies the control process.

- Lower regeneration temperature: extra-dehumidification rate due to direct humidification is avoided, thus a lower temperature regeneration is required, maximizing the efficiency of the solar system.

\subsubsection{Target summer/winter}

The controller's goal is to maintain the supply air temperature within the range of $20^{\circ} \mathrm{C}$ to $24^{\circ} \mathrm{C}$ (climatic curve) and to limit the supply air humidity ratio to a certain value (e.g. $9.5 \mathrm{~g} \mathrm{~kg}-1$ ). Dehumidification can be provided only by means of the desiccant rotor and the target supply air humidity is reached only when sufficient solar heat is available. Therefore, the target humidity shall be intended as a desired condition which sometimes could not be met. Moreover, in the considered climate (south European), humidification in winter is uncommon practice, thus it is not foreseen. Target temperatures are strict requirements and the heat pump in summer allows reaching the desired supply temperature even if a hot backup is not present on the regeneration stream and the direct evaporative cooling is not employed. The climatic curve that has been theoretically studied [15] leads to the following rules. In summer, the temperature set point varies from $24^{\circ} \mathrm{C}$, when external temperature is lower than $26^{\circ} \mathrm{C}$, to $22^{\circ} \mathrm{C}$, during the warmer hours. In winter, the climatic curve varies from $20^{\circ} \mathrm{C}$ at low temperature and to $22^{\circ} \mathrm{C}$ for higher temperature.

\subsection{Selected configuration}

\subsubsection{General description}

The installed system (Fig. 1) integrated a non-conventional DEC AHU with a solar thermal system and an electric-reversible heat pump (HP). During the summer, the HP cooled the supply air (Active Cooling) and pre-heated the regeneration air (when dehumidification was needed). The remainder of the regeneration thermal energy was provided by solar energy. During the heating season, if needed, a heating coil heated the supply air (Active Heating), using thermal energy drawn from the solar tank, the HP or the back-up heater (BUH).

The main features of the installed SDEC system and the differences from a standard DEC system are listed below:

- Regeneration process: external air is used instead of return air, in a dedicated channel.

- Regeneration heat: provided by the HP condenser (heats the pre-regeneration coil) and the solar array (heats the regeneration coil);

- Hybrid scheme: a traditional cooling coil, cooled by the HP evaporator, replaces direct evaporative coolers;

- Static heat exchanger, namely HX, instead of a standared rotary heat exchanger;

- Bypasses, namely BP: the desiccant wheel and the static heat exchanger can be bypassed with PI controlled shutters.

\subsubsection{Control strategy definition}

In general, AHU controllers use sequencing logic in order to maintain the desired comfort conditions in the most economical way. One drawback of this approach is the risk of instability when several components are controlled at the same time. This problem can be partly addressed in the tuning phase of the control parameters, an approach which tends to produce a sluggish controller [17]. Sequencing logic applied to DEC systems may result in a complex tuning exercise due to the number of components involved. Therefore, alternative approaches have been investigated in which
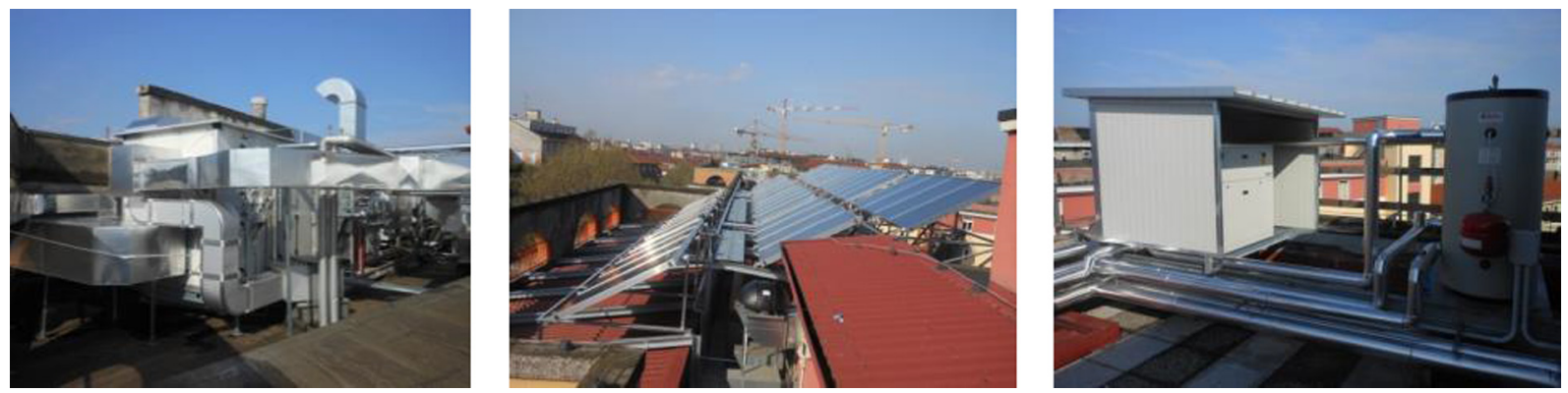

Fig. 1. Photos of the installation, from the left: DEC AHU, solar collector field and the electric heat pump. 
a subset of components are operated steadily according to some rules $[18,13]$ and only a limited number of components use feedback control simultaneously. The definition of various 'operation modes', as free cooling, indirect evaporative cooling, active cooling, allows this particular operation. The transition from one operation mode to another one is managed by a selector which can be based on simple heuristic rules. Actuator use can be reduced by adopting a finite state machine approach [17], i.e. delaying the transition until the current operation mode has reached saturation for a predefined time interval. In the following, the analysis of the system operation modes is presented and the adopted control logic is described. The DEC system operates at constant and balanced flow rates $\left(5000 \mathrm{~m}^{3} / \mathrm{h}\right)$, which are the minimum required, at the given application, for pollution control requirements. Neutral primary air shall be supplied to the conditioned space, i.e., $\mathrm{T}_{\mathrm{SA}, \min }=20^{\circ} \mathrm{C}$, $\mathrm{T}_{\mathrm{SA}, \max }=24{ }^{\circ} \mathrm{C}$. The maximum supply air humidity $\mathrm{x}_{\mathrm{SA}, \max }$ is fixed at $9.5 \mathrm{~g} \mathrm{~kg}^{-1}$.

Due to the higher interest in summer configuration, the following summer modes are presented in detail, while winter operations are roughly described.

2.2.2.1. Cooling modes. When external air is good to be supplied to the internal ambient, no air treatment is required. In this case, the simplest operation mode is activated, Free Cooling (FC). In this operation mode only VE1 and VE2 operate, while desiccant wheel bypass BP1 and heat exchanger bypass BP2 are open.

When external air temperature becomes high and supply air temperature falls above the set point dead band limit, the Indirect Evaporative Cooling (IEC) activates. In this configuration, the return humidifier is activated for adiabatic cooling of return air until Ta8. The static heat exchanger provides sensible exchange with supply air, by PI control of the bypass BP2. The target of the PI control is the supply air temperature Ta5.

If external conditions are too hot and/or humid for IEC mode, Active Cooling (AC) mode operates; electric heat pump is activated, together with P5 and P4 pumps. The cooling energy is provided through the supply air coil and the supply air temperature is adjusted with PI control of the CV2 valve. The condenser heat is rejected through the return air stream or the pre-regeneration coil, i.e. coil B3 (if dehumidification mode is active).

2.2.2.2. Dehumidification mode. In the De-Humidification mode (DH), the upper half of the desiccant wheel adsorbs the water vapour present in the supply air stream. The desorption of the water in the lower half (regeneration process) is provided by the regeneration air stream, heated up by solar energy and/or by the pre-regeneration coil fed by heat pump condenser. VE3 fan is on, while BP1 is closed in order to force supply air through the wheel. The regeneration air temperature is adjusted via the CV1 PI control, with supply air humidity $\mathrm{x} 6$ as control target.

2.2.2.3. Heating modes. In winter, the heating supply is done via different strategies. In heat recovery mode, only the static heat exchanger provides heat to the supply air, through heat recovery from return air. With higher heating loads, the intervention of supply air coil is necessary. The supply coil has three possible sources:

- Solar energy, stored in the solar tank;

- Heat pump, which is reversible, with supply air as heat sink and solar tank and/or return air as heat source;

- Backup heater, via heat back up (HBK) heat exchanger.

2.2.2.4. Safety modes. Some additional operative modes have been developed and implemented through the first monitoring period. The aim of these modes is to prevent potentially dangerous situations, preserving the correct operation of the plant and the components lifetime. They are listed below.

- Antifreeze control: when the external air temperature falls below a certain limit, the circulating pumps are turned on at low flow rate (if not active).

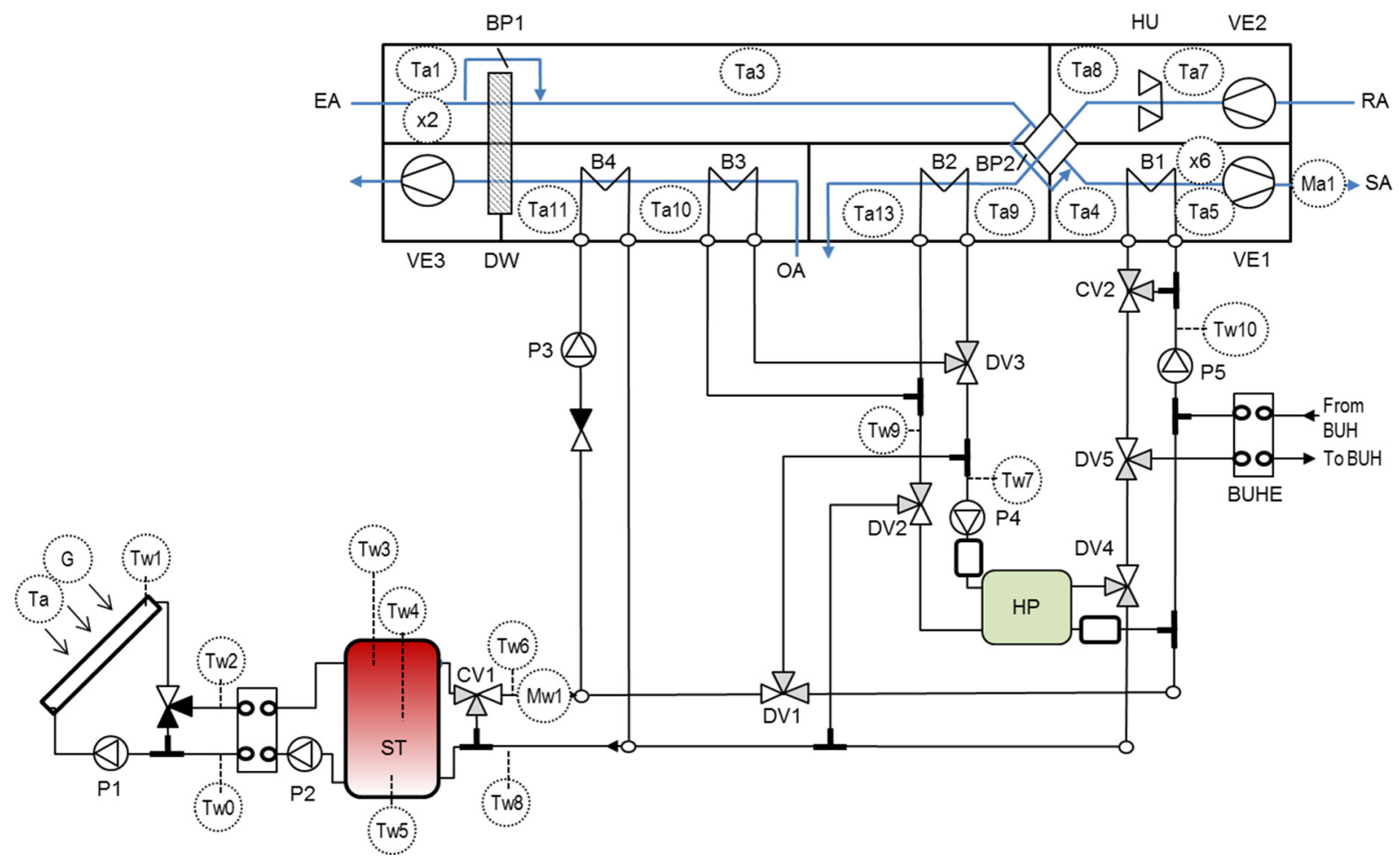

Fig. 2. Plant scheme and installed sensors for air temperature (Ta), air absolute humidity (x), air volume flow rates (Ma) and water temperature (Tw). 
- Transition mode (heat pump): defined to dissipate the heat generated at the condenser side of the heat pump once the compressor stop due to the change of modality. This mode is necessary every time the control logic pushes the plant out from a heat pump mode and introduces a delay in the shutdown of the pumps P4 and P5.

- Condensation temperature of the heat pump: when water temperature at the inlet of condenser side of the heat pump reaches $45^{\circ} \mathrm{C}$, the heat pump compressors stop due to overheating alarm. This alarm requires the maintenance staff intervention to reset manually the heat pump operation. To avoid this situation, when Tw7 temperature is above $44^{\circ} \mathrm{C}$ the heat pump compressors are turned off, while P4 and P5 pumps are still working with the aim of dissipate condenser heat and reduce Tw7 (via the activation of transition modes).

- Anti-stagnation mode: the plant configuration is similar of the dehumidification mode, but the wheel is off, the BP1 is open and CV1 is fully open. In this way, the exceeding heat produced by the solar collectors is dissipated through the regeneration coil and it is possible to keep the collectors' temperature under the stagnation limit.

2.2.2.5. Control logic. The transition from one mode to another is managed by a finite state machine control logic. A simplify description of the different transitions is described below and based on cooling or heating loads (Fig. 3).

The implemented control strategy has a more advanced logic and the following two figures represent a detail description of principal summer modes for supply air temperature control (Fig. 4) and stagnation and humidity control (Fig. 5). These two control logics are run in parallel and does not have direct link. Nevertheless, when the dehumidification is activated the sensible cooling load increases drastically thus the supply air temperature control is pushed to active cooling mode. Dashed arrows represent transitions toward lower-level modes, full arrows toward higher-level modes. The transition conditions are presented in bold, while saturation conditions are presented in italic.

For humidity and stagnation control, parameters under investigation are the humidity of supply air $\mathrm{x} 6$, the solar tank temperature Tw4 and the collector temperature Tw1.

\subsubsection{System's components}

The hybrid solar DEC system is subdivided in three sub-systems. The first one is the solar system that generates renewable heat used in the regeneration process of the desiccant wheel in summer and the air heating process in winter. The second one is the water/water heat pump that allows transferring heat between different levels of temperature. The last one is the air handling unit that modifies the external air condition to reach the required temperature and humidity.

2.2.3.1. Solar system. The solar system is composed of 11 large solar collectors, for a total absorber area of $102 \mathrm{~m}^{2}$. The peak production is $67.2 \mathrm{~kW}_{\text {th }}$ for an irradiation of $1000 \mathrm{~W} / \mathrm{m}^{2}$ under nominal summer condition. The solar energy generated is transferred to the secondary loop thanks to the flat plate heat exchanger of a nominal power of $52 \mathrm{~kW}$ and a LMTD of $3.7 \mathrm{~K}$ and stored into a $5 \mathrm{~m}^{3}$ solar heat storage. The water temperature used to the AHU side is controlled thanks to the mixing valve CV1 in order to control the supply absolute humidity in summer or to control the supply temperature in winter. The main characteristics of the solar system are summarized in the Table 1.

2.2.3.2. Water/water heat pump. Condenser and evaporator of the water/water heat pump exchange heat with two water loops. Specifically, in summer operation mode the evaporator is connected to coil B1 and the condenser is connected to coils B2 and B3. In winter operation mode, the condenser exchanges with coil B1 and the evaporator exchanges with coil the B2 or/and with the solar tank. The winter heating load and the summer cooling load of the heat pump can reach $10 \mathrm{~kW}$ and $20 \mathrm{~kW}$, respectively. Ideally, a variable capacity heat pump would adapt its power according to the load to maintain steady state condition. A contin-uous modulation is nowadays feasible with an inverter but commercially not available for water/water small capacity units. An alternative is discrete modulation with compressors in parallel. In this specific case, the nominal heating load and cooling load are, respectively $32.9 \mathrm{~kW}$ and $27.4 \mathrm{~kW}$, and the modulation is done thanks to two identical compressors in parallel, which lead to two modulation steps: $50 \%-100 \%$ of the nominal conditions. In order to match the real load, two buffer tanks of 500 litres have been introduced in the evaporation and condensation sides in addition to a mixing valve (CV2) to control the supply air temperature. The QC and $\mathrm{COP}_{\mathrm{e}, \mathrm{WW} \text {-HP }}$ are function of the outlet temperature at the evaporation and condensation loops (Fig. 6). They are derived from the manufacturer's data sheet. For temperatures out of the data sheet range, a constant $\mathrm{COP}_{\mathrm{e}, \mathrm{WW}-\mathrm{HP}}$, equal to the correspond-ing value at the temperature range boundary, is assumed. Recirculation pumps P4 and P5, on the evaporation and condensation loops, show electrical power consumptions slightly variable with the valve position, about $0.42 \mathrm{~kW}$ and $0.35 \mathrm{~kW}$, respectively.

Increasing sensible heating loads

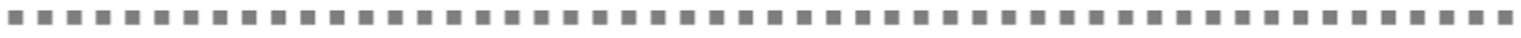
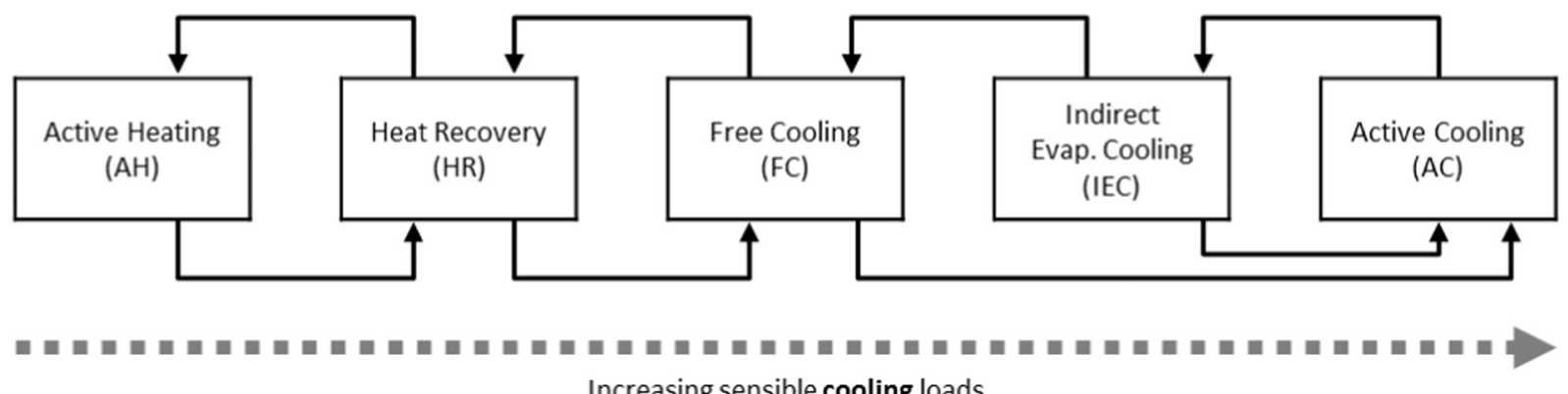

Increasing sensible cooling loads

Fig. 3. Schematics of the Finite State Machine Control logic for supply air control. 


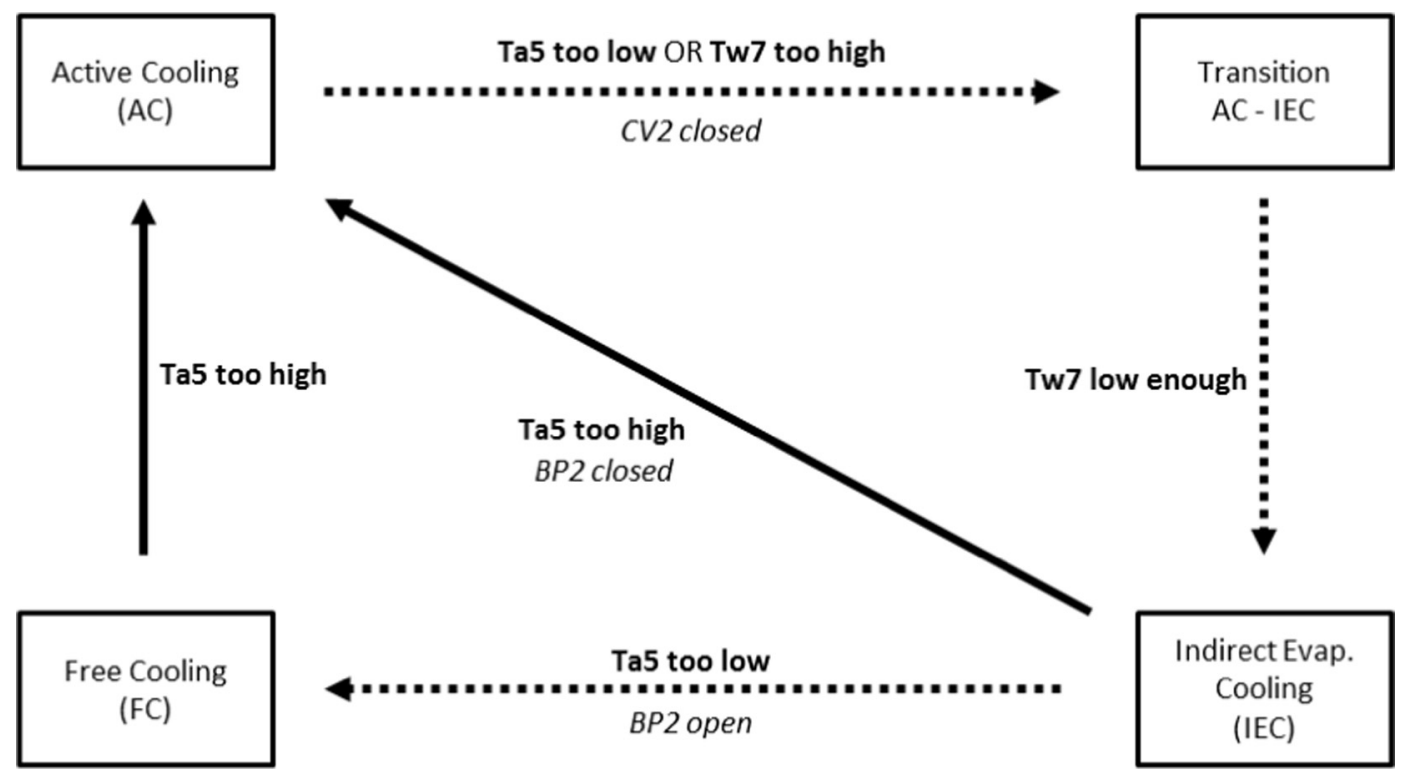

Fig. 4. Supply air temperature control.

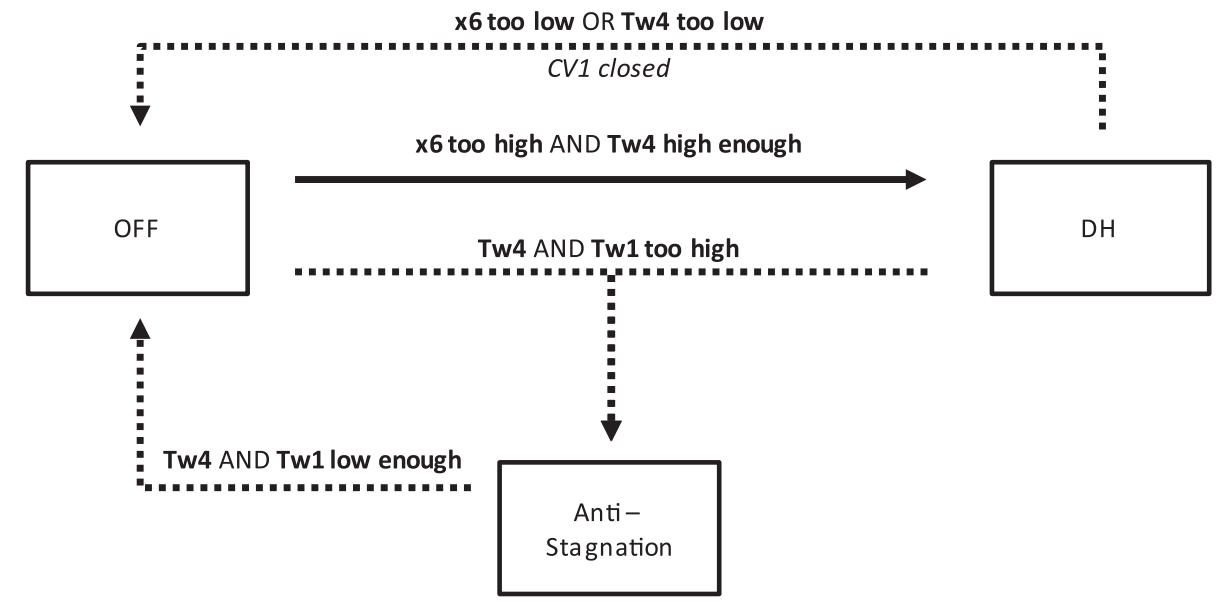

Fig. 5. Stagnation and humidity control.

Table 1

Solar system characteristics.

\begin{tabular}{lll}
\hline Component & Technical features & Value \\
\hline Solar field & Optical efficiency - $\eta_{0}$ & 0.809 \\
& Heat loss coefficient a1 $\left(\mathrm{W} / \mathrm{m}^{2} \mathrm{~K}\right)$ & 2.858 \\
& Heat loss coefficient a2 $\left(\mathrm{W} / \mathrm{m}^{2} \mathrm{~K}^{2}\right)$ & 0.015 \\
& Incident angle modifier at $50^{\circ}$ & 0.95 \\
\multirow{3}{*}{ Heat exchanger } & Total absorber area $\left(\mathrm{m}^{2}\right)$ & 102 \\
& LMTD in summer conditions (K) & 3.7 \\
Thermal Storage & Heat Exchanged in summer conditions $(\mathrm{kW})$ & 52 \\
\multirow{2}{*}{ Electrical pumps } & 5 \\
& Insulation thickness (mm) & 120 \\
& Primary loop (P1) power consumption $(\mathrm{kW})$ & 0.3 \\
& Secondary loop (P2) power consumption $(\mathrm{kW})$ & 0.2 \\
\hline
\end{tabular}

2.2.3.3. Air handling unit. The air handling unit designed for this specific application has several peculiarities with respect to standard DEC units. In fact, it is composed of three channels, supply, return and regeneration, instead of two as in a standard DEC system. On the supply stream two bypasses (BP1 and BP2) are installed to minimize the pressure drops when the desiccant wheel (DW) or the static heat exchanger (HX) are not used. The fan electrical power on the supply stream is $1.9 \mathrm{~kW}$ when the two bypass dampers are closed, $1.6 \mathrm{~kW}$ when BP1 is opened, and 1.0 $\mathrm{kW}$ when they are both fully open. For the return and regeneration streams the fan electrical powers are respectively $1.3 \mathrm{~kW}$ and 1.3 $\mathrm{kW}$. The supply air is subjected to the following transformation: first, the desiccant wheel dehumidifies the supply air and at the same time increases its temperature. The slow motion of the desiccant wheel requires an electrical power consumption of $0.2 \mathrm{~kW}$. For a regeneration temperature of $60^{\circ} \mathrm{C}$ and a supply air at $32^{\circ} \mathrm{C}$ and $14 \mathrm{~g} / \mathrm{kg}$, the experimental test performed on a similar desiccant wheel leads to a temperature increase of $14.9{ }^{\circ} \mathrm{C}$ and a humidity decrease of $4.6 \mathrm{~g} / \mathrm{kg}$. This transformation is proportional to the temperature regeneration, and supply humidity can be controlled through this temperature. This dry and hot air release some sensible heat to the return stream with a heat exchanger. A fixed air/air heat exchanger (HX) is used, instead of the standard heat exchanger wheel, which has a temperature efficiency under summer condition of $72 \%$. This cooling process proceeds to reach the supply temperature set point with the cooling coil B1, with a temperature efficiency of $76.5 \%$. Water/water heat pump generates the chilled water used in the cooling coil B1. To maximise the passive cooling of the air/air heat exchanger, the return stream is cooled down 

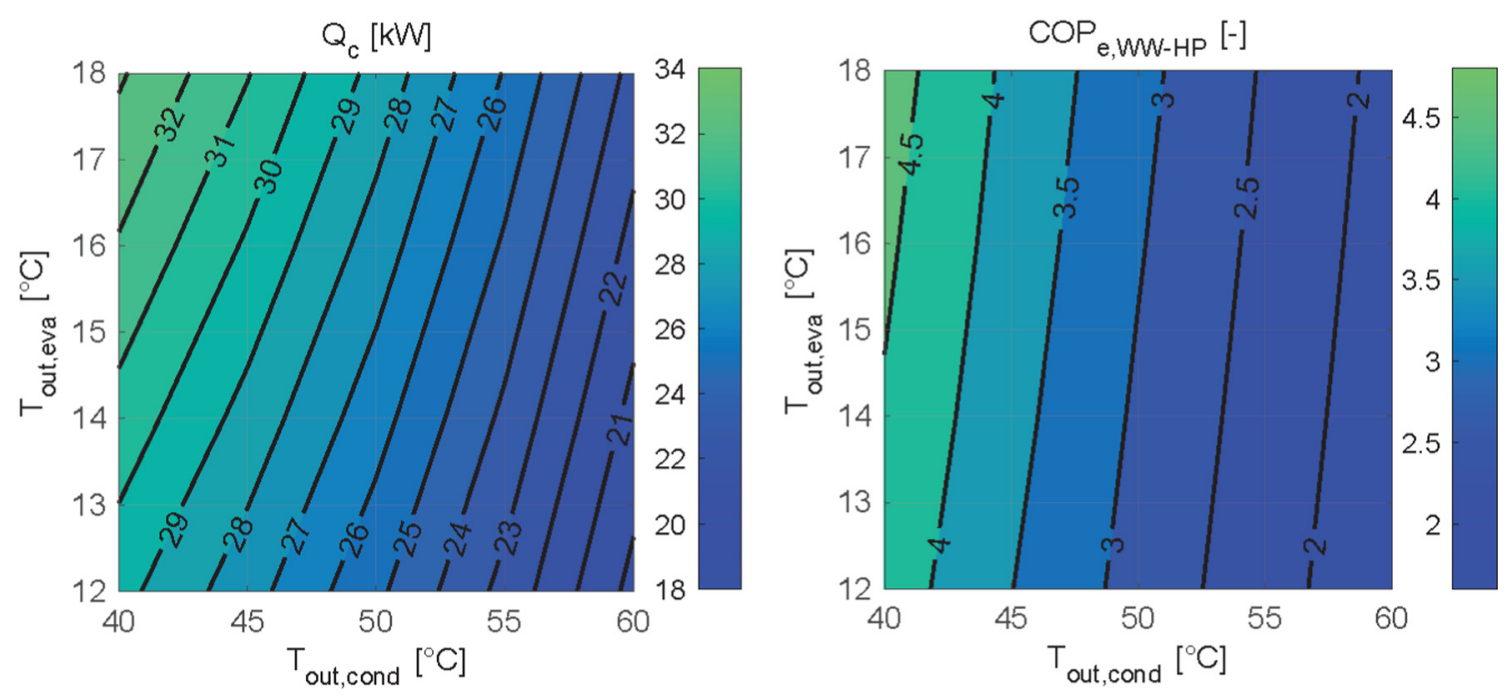

Fig. 6. Qc and $\mathrm{COP}_{\mathrm{e}, \mathrm{WW}-\mathrm{HP}}$ of the water/water heat pump.

through a humidifier with an isenthalpic efficiency of $90 \%$ and an electrical power consumption of $0.2 \mathrm{~kW}$. Upstream of the heat exchanger, the warm and humid return air is used as heat sink for the condensation loop of the heat pump. The coil B2 has a temperature efficiency of $50 \%$. In order to avoid any contamination of the supply air, the regeneration stream is using fresh external air. To reach the desired temperature regeneration two heating coils are used in series. The first coil, B3, preheats the air thanks to the rejected heat from the heat pump, with a temperature efficiency of $78 \%$, whereas the second one, with a temperature efficiency of $83.3 \%$, uses the solar heat from the solar tank. The electrical power of pump P3 that connects the solar storage to the coil B4 is 0.30 $\mathrm{kW}$. Based on desiccant wheel data sheet the following interpolation formula is used, see eq. 1 and 2 . This interpolation is based on the temperature difference between ambient air and regeneration temperature, noted $\Delta \mathrm{T}[\mathrm{K}]$, and the specific enthalpy of the ambient air, noted $\mathrm{h}[\mathrm{k}]$. The coefficients of eq. 1 and 2 are reported in Table 2.

$$
\begin{aligned}
\Delta T_{D W, S A}= & a_{00}+a_{10} \Delta T+a_{01} h+a_{20} \Delta T^{2}+a_{11} \Delta T h+a_{02} h^{2} \\
& +a_{30} \Delta T^{3}+a_{21} \Delta T^{2} h+a_{12} \Delta T h^{2}+a_{03} h^{3} \\
\Delta x_{D W, S A}= & b_{00}+b_{10} \Delta T+b_{01} h+b_{20} \Delta T^{2}+b_{11} \Delta T h+b_{02} h^{2} \\
& +b_{30} \Delta T^{3}+b_{21} \Delta T^{2} h+b_{12} \Delta T h^{2}+b_{03} h^{3}
\end{aligned}
$$

Fig. 7 summarizes the airflow processes at nominal conditions in the three channels on a psychometric chart.

\subsection{Summer nominal condition}

In this Section, the expected performance under summer condition is presented.

\subsubsection{Definition of the nominal condition}

The summer nominal condition is defined for a hot and humid day, i.e. an external air condition of $32{ }^{\circ} \mathrm{C}$ and $14 \mathrm{~g} / \mathrm{kg}$. In this speci- fic case, the two bypasses of the desiccant wheel and the static heat exchanger are closed, the dehumidification and the active cooling (with heat pump and humidifier) modes are active.

The return air is assumed equal to $26^{\circ} \mathrm{C}$ and $50 \%$ of relative humidity. The mass flow rates of the three streams are balanced and equal to $5000 \mathrm{~m}^{3} / \mathrm{h}$. The peak solar gain is calculated with an irradiation of $1000 \mathrm{~W} / \mathrm{m}^{2}$ at noon.

\subsubsection{Results}

The air transformation of the three streams is done under steady state condition based on the installed component characteristics. The regeneration temperature is calculated iteratively using eq. 1 to reach the supply humidity. The outlet water temperatures of the heat pump are calculated iteratively to reach the temperature set point on the supply stream and to balance the rejected heat from the condensation side. On Fig. 8, the temperature, the absolute humidity and the specific enthalpy is presented with the power contribution of each component.

Under summer conditions, based on the solar heat exchanger characteristic, the average solar field temperature is $64.3^{\circ} \mathrm{C}$, which means that the minimum solar irradiation to balance the solar heat load is $660 \mathrm{~W} / \mathrm{m}^{2}$.

\subsubsection{Performance figures}

From the previous results, some preliminary considerations can be highlighted. The cooling power is $36.3 \mathrm{~kW}_{\text {th }}$ where $75 \%$ is coming from passive cooling and the overall electrical power consumption is $8.4 \mathrm{~kW}_{\mathrm{e}}$ including the heat pump, the fans, the humidifier pump, the rotor motor and the pumps. Thus, the expected PER for the overall system, defined in Section 3 Performance evaluation, is 1.73 , where the conversion coefficient to primary energy electricity is 2.5 . Seventy-seven (77) percent of the regeneration heat is provided by solar heat with an inlet water temperature of $64.3^{\circ} \mathrm{C}$. The outlet temperature on the condensation side is $40.1^{\circ} \mathrm{C}$ with a temperature difference on the conden-

\begin{tabular}{|c|c|c|c|c|c|c|c|c|c|c|}
\hline & 00 & 10 & 01 & 20 & 11 & 02 & 30 & 21 & 12 & 03 \\
\hline $\mathrm{a}$ & $-2.31 \mathrm{E}+00$ & $4.65 \mathrm{E}-01$ & 7.52E-02 & $-5.20 \mathrm{E}-04$ & $1.61 \mathrm{E}-03$ & $-8.00 \mathrm{E}-04$ & $-8.82 \mathrm{E}-06$ & $1.86 \mathrm{E}-06$ & $-4.20 \mathrm{E}-06$ & $2.93 \mathrm{E}-06$ \\
\hline $\mathrm{b}$ & $1.38 \mathrm{E}-03$ & $-1.60 \mathrm{E}-04$ & $-4.32 \mathrm{E}-05$ & $3.96 \mathrm{E}-07$ & $-5.17 \mathrm{E}-07$ & $4.41 \mathrm{E}-07$ & $4.88 \mathrm{E}-09$ & $-1.65 \mathrm{E}-10$ & $-3.17 \mathrm{E}-10$ & $-1.58 \mathrm{E}-09$ \\
\hline
\end{tabular}
sation side of $5^{\circ} \mathrm{C}$. In this specific case, the coil B2 has a very

Table 2

Eq. (1) and (2) coefficients. 


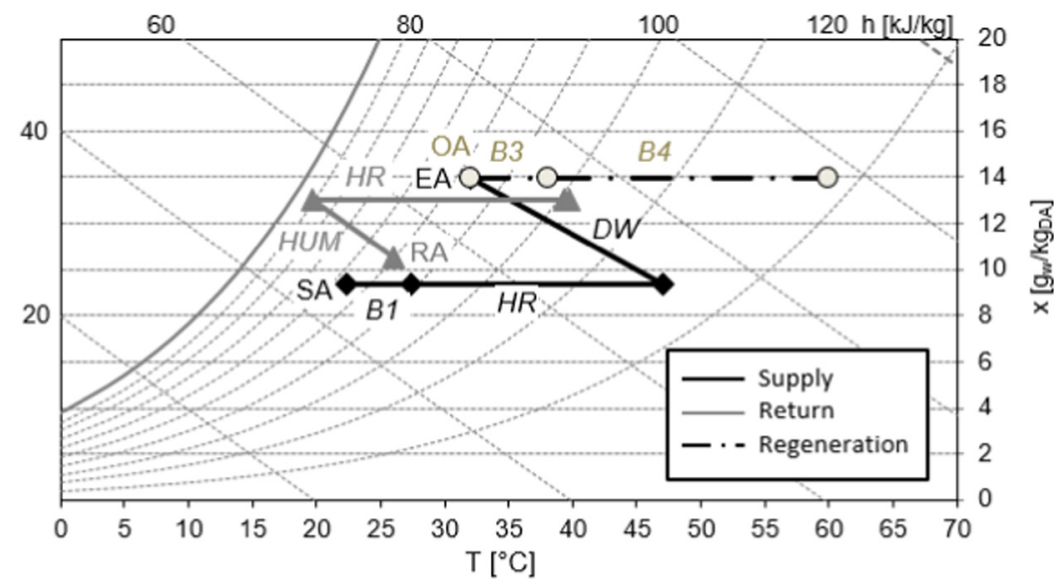

Fig. 7. Psychometric flow chart for the summer mode at nominal condition.

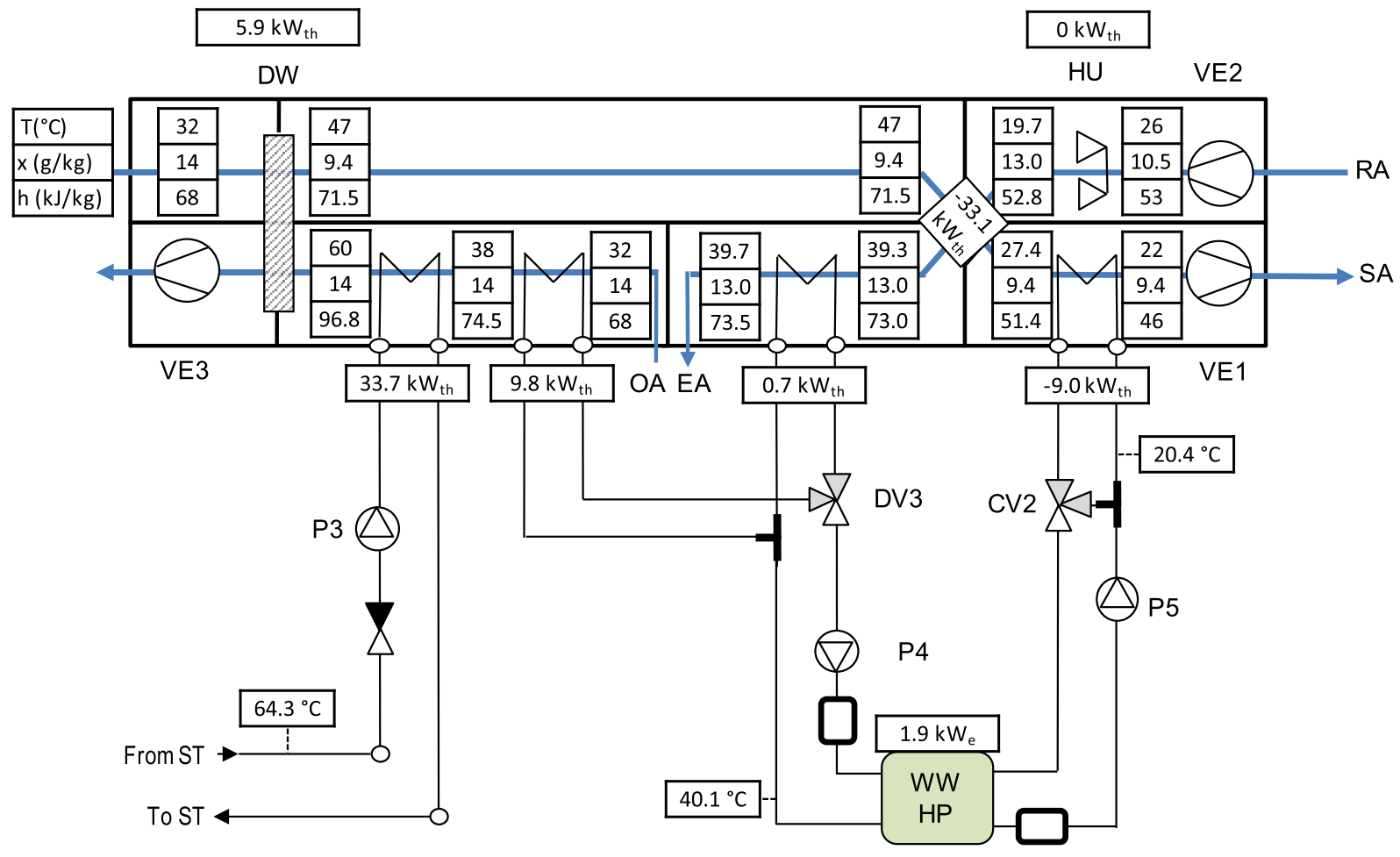

Fig. 8. Plant conditions under summer nominal conditions.

small contribution but it is crucial in case of higher heat rejection from the heat pump condenser in order to limit the increase of the condensation temperature. In this specific case, the use of a third channel, instead of the contaminated return air, requires a higher regeneration heat load due to lower temperature and higher absolute humidity of the outdoor air compared to the exhaust air.

\section{Performance evaluation}

The objective of this Section is to evaluate the system performance and to define a methodology to quantify it. A specific methodology is required since the performance evaluation of renewable energy driven air handling system is strongly dependent to the boundary conditions. Therefore, it has been developed the approach hereafter described. First, performance figures are defined (Section 3.1) to compare expected and monitored perfor- mance under several characteristic days. Secondly, the accuracy of monitored performance has been calculated under nominal conditions (Section 3.2). Then, characteristic summer days of July 2015 are identified and discussed in Section 3.3. Lastly, the monitoring data are discussed and compared to a reference system (Sec-tion 3.4) and to the expected performance of the hybrid solar DEC system (Section 3.5).

\subsection{Performance figures}

The cooling effect is defined as the enthalpy rate difference between the ambient air and the supply air, as defined in Eq. (3).

$\dot{Q}_{u f l}=\left(h_{E A}-h_{S A}\right) \cdot \dot{m}_{1}[k W]$

The overall performance figures of the hybrid solar DEC system, Solar Fraction, electrical COP and Primary Energy Ratio, are defined below: 
$S F_{\text {th }}=\frac{\dot{Q}_{B 4}}{\dot{Q}_{B 3}+\dot{Q}_{B 4}}=\frac{\dot{Q}_{B 4}}{\dot{Q}_{\text {reg }}}[-]$

$\mathrm{COP}_{e}=\frac{\dot{Q}_{\text {ufl }}}{\sum_{i} \dot{P}_{i}}[-]$

$P E R=\frac{\dot{Q}_{\text {ufl }}}{\sum_{i} \dot{P}_{i} \cdot P E F_{e}+\sum_{i} \dot{Q}_{i} \cdot P E F_{t h, i}}[-]$

where: $\sum_{i} \dot{P}_{i}$ and $\sum_{i} \dot{Q}_{i}$ are respectively the sum of all the electric power (i.e. heat pump, fans, circulation pumps, humidifier pump and rotor motor) and thermal power (e.g., heat generated by a backup heater) consumptions of the system, $P E F_{e}$ is the primary energy factor for electricity generation (here assumed equal to 2.5) and $P E F_{t h}$ is the primary energy factor for thermal energy gen-eration. In this work, the thermal power consumption of the system is null as only renewable energy (solar heat) is used.

\subsection{Measurement apparatus}

The air-handling unit is equipped with 12 air temperature sensors distributed over the three channels, see Fig. 2, and two humidity sensors at the inlet and outlet of the supply stream. As air temperatures in each cross section of the air handling unit are not uniform, averaging temperature sensors (PT100) have been installed, in order to improve the quality of the measurement. One air volume flow rate sensor is monitoring the supply stream and three pressure drop sensors are installed on each fan. One water temperature sensor is installed on each water loop, i.e. solar regeneration loop and the two sides of the heat pump (condensation and evaporation). For the solar system, eight water immersed temperature sensors, one air temperature sensor, one magnetic flow rate sensor and one pyranometer are installed. The sensors are listed in Table 3 with their respective uncertainties.

To calculate energy balance on the air side is an issue due to the measurement uncertainties (Table 3). For the high temperature, high humidity reference condition (Fig. 8), the measurement uncertainties are presented in Table 4.

The error propagation analysis for useful cooling power calculation $\dot{Q}_{u f}$ leads to an error of $\pm 5.5 \%$ (about $\pm 1.99 \mathrm{~kW}$ ). As the electrical counter has a $0.5 \%$ of uncertainty rate, the PER value in nominal condition is affected by an error of 5.5\%.

\subsection{Characteristic days}

In this Section two summer seasons of operation of the system are characterized through the analysis of several operation days, called "characteristic days". The characteristic days reflect: the main operation modes of the system, different boundary conditions (among which the design nominal conditions), the lowest possible measurement uncertainties, local quasi steady state behaviours and behaviour unexpected during the system design phase. Thus, the selected monitoring data show the actual performance and control flexibility of an on-site hybrid solar DEC.

Firstly, the active cooling mode (AC) has been analysed for four days. Lastly, an unintended case, where the heat pump is off due to an internal malfunctioning, at a later time fixed, has been analysed. The charts below show for each day the main boundary conditions and the most significant system outputs. The main boundary conditions are the external air temperature and humidity by mass $\left(T_{a 1}\right.$ and $\mathrm{x}_{2}$ ) and the outlet temperature of the AHU return side wetted media humidifier $\left(T_{a 8}\right)$. On the other hand, the most significant system outputs are: the supply air temperature and humidity by mass $\left(T_{a 5}\right.$ and $\left.x_{6}\right)$, the regeneration air temperature $\left(T_{a 11}\right)$, the PER and the useful total cooling power, reported with a scale factor of 20 $\left(\dot{Q}_{\text {uf }} / 20\right)$ for the sake of graphical clarity.

Figs. 9 and 10 show two days when the AC and DH operation modes are on as both the external air temperature and humidity are constantly higher than the set-points during the daytime. On the 1st of July (Fig. 9) the system manages to maintain the humidity by mass set-point for the whole day, thanks to a relatively low regeneration temperature needed $\left(40-50^{\circ} \mathrm{C}\right)$, which extends the use of the solar energy stored in the hot water tank during the night time. Also, the supply air temperature set-point $\left(T_{a 5} \approx 22\right.$ ${ }^{\circ} \mathrm{C}$ ) is well guaranteed along the day. The useful cooling effect range between $6 \mathrm{~kW}$ during the colder night hours to a maximum of $30 \mathrm{~kW}$ at the warmest hours. Lastly, about the PER, the actual maximum value is around 1.1 at the hour 4360 , indeed the short PER peaks have to be neglected as they represent the time interval when the heat pump is off and the system exploit its thermal inertia to deliver roughly the same cooling power for short time interval. On the other hand, the $25^{\text {th }}$ of July (Fig. 10) is warmer and more humid. Thus, although the system still manages to produce a maximum cooling power of $30 \mathrm{~kW}$ with a PER around 1.0, it is not enough to guarantee exactly the set-point condition. In partic-ular, the higher dehumidification required during this day implies that a relatively high regeneration air temperature is needed $\left(60^{\circ} \mathrm{C}\right)$. The physical explanation is that the periodical change in water load of the desiccant material has to increase in such condition,

Table 3

Sensor accuracy.

\begin{tabular}{|c|c|c|c|c|c|}
\hline Measure & Unit & Type & Operation range & Uncertainty & Source \\
\hline Air flow rate & $\mathrm{m}^{3} / \mathrm{h}$ & $\begin{array}{l}\text { dP transducer, coupled with a X } \\
\text { grid flowmeter }\end{array}$ & - & $\begin{array}{l}\mathrm{dP} \text { uncertainty } \pm 0.5 \% \\
\mathrm{X} \text { grid uncertainty } \pm 5 \%\end{array}$ & Data sheet \\
\hline Water flow rate & $\mathrm{m}^{3} / \mathrm{h}$ & Electro-magnetic flow meter & $\begin{array}{l}\text { Max fluid speed } 10 \mathrm{~m} / \mathrm{s} \\
\text { Temperature range }-40{ }^{\circ} \mathrm{C} /+80 \\
{ }^{\circ} \mathrm{C}\end{array}$ & $\pm 5 \%$ & Empirical measurement \\
\hline Air temperature & ${ }^{\circ} \mathrm{C}$ & Pt100 & $\begin{array}{l}\text { Temperature range }-30^{\circ} \mathrm{C} /+70 \\
{ }^{\circ} \mathrm{C}\end{array}$ & $\pm(0.3+0.005 \cdot \mathrm{T})^{\circ} \mathrm{C}$ & Class B EN 60751 \\
\hline Water temperature & ${ }^{\circ} \mathrm{C}$ & Pt100 & $\begin{array}{l}\text { Temperature range }-50{ }^{\circ} \mathrm{C} /+350 \\
{ }^{\circ} \mathrm{C}\end{array}$ & $\pm(0.15+0.002 \cdot \mathrm{T})^{\circ} \mathrm{C}$ & Class A EN 60751 \\
\hline Relative humidity & $\mathrm{RH} \%$ & Capacitive thermo-hygrometer & $\begin{array}{l}\text { Measuring range } 0-100 \% \\
\text { Temperature range }-30{ }^{\circ} \mathrm{C} /+70 \\
{ }^{\circ} \mathrm{C}\end{array}$ & $\pm 2 \%$ & Data sheet \\
\hline Irradiation & $\mathrm{W} / \mathrm{m}^{2}$ & Thermopile solarmeter & $\begin{array}{l}\text { Max irradiance } 2000 \mathrm{~W} / \mathrm{m}^{2} \\
\text { Temperature range }-40{ }^{\circ} \mathrm{C} /+80 \\
{ }^{\circ} \mathrm{C}\end{array}$ & $\pm 5 \%$ & Class 1 ISO 9060 \\
\hline Electrical Counter & $\mathrm{kW}$ & electric power transducer & - & $\pm 0.5 \%$ & Data sheet, EN 50470-3 \\
\hline
\end{tabular}


Table 4

Measurement uncertainties.

\begin{tabular}{|c|c|c|c|c|}
\hline & Value & Relative uncertainty & Absolute uncertainty & Units \\
\hline Ta1 & 32 & $1.44 \%$ & 0.460 & ${ }^{\circ} \mathrm{C}$ \\
\hline Ta5 & 22 & $1.86 \%$ & 0.410 & ${ }^{\circ} \mathrm{C}$ \\
\hline RH2 & 46.9 & $2 \%$ & 0.939 & $\%$ \\
\hline RH6 & 56.9 & $2 \%$ & 1.139 & $\%$ \\
\hline Ma1 & 5000 & $2 \%$ & 100 & $\mathrm{~m}^{3} / \mathrm{h}$ \\
\hline $\mathrm{P}$ & 8.4 & $0.5 \%$ & 0.04 & $\mathrm{~kW}_{\mathrm{e}}$ \\
\hline
\end{tabular}

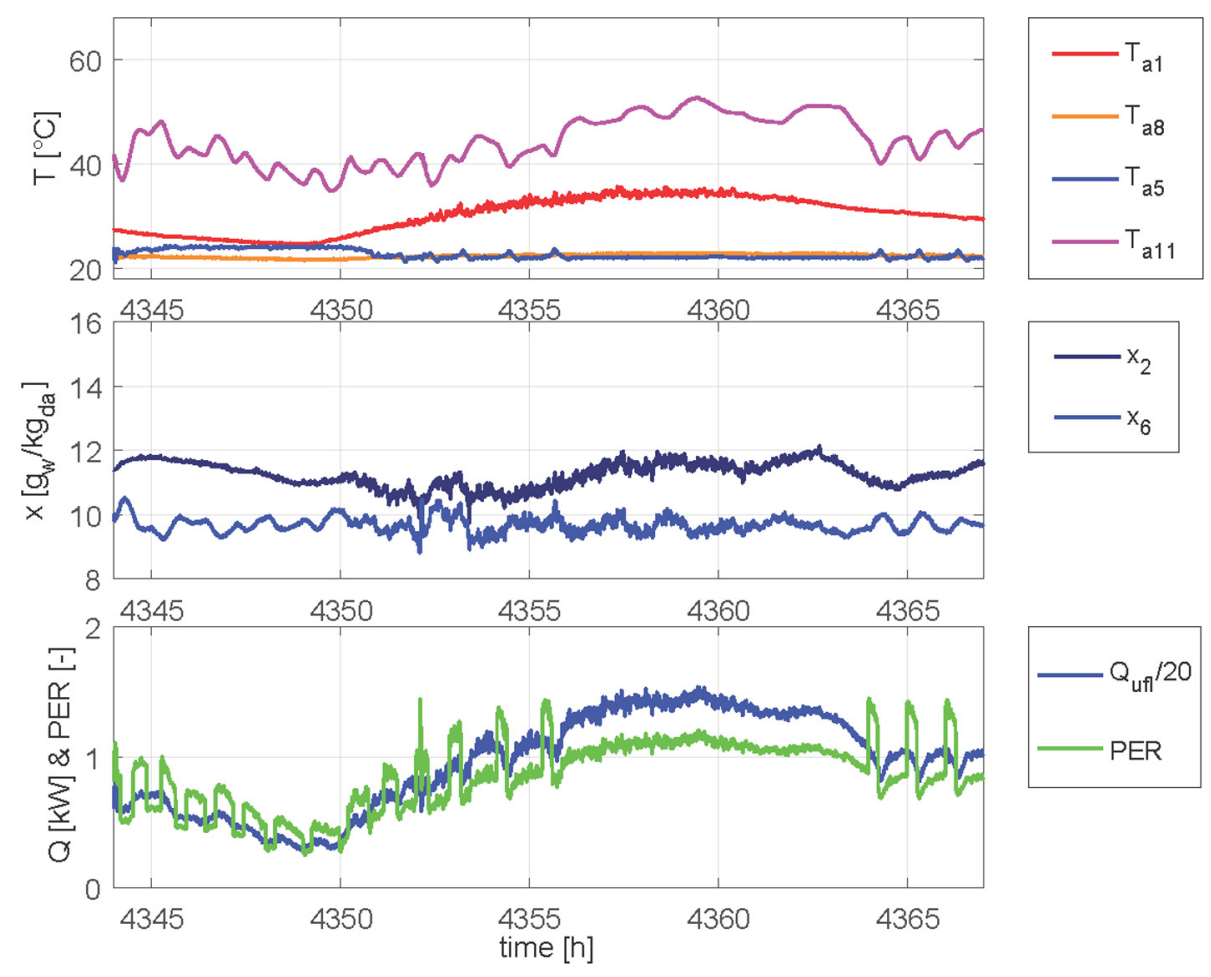

Fig. 9. 1st of July - DH + HP.

and this could be achieved by reducing the minimum water load at the end for the regeneration phase. Since water load and equilibrium relative humidity are nearly proportional for the desiccant material (silica gel), the regeneration air must reach a lower value of relative humidity, achievable by means of a higher air temperature. By consequence, the heat demand for the regeneration increases, and the solar energy available is not enough to guarantee the requested dehumidification, especially during night hours. Fig. 11 shows a day with external conditions similar but slightly more restrictive respect to Fig. 10, since ambient temperature and humidity are higher especially during the first half of the day. Since dehumidification need is higher, regeneration temperature increases and a higher cooling load is required to the heat pump. In this case, control logic generates an on/off cycling of the heat pump compressors. Indeed, the heat pump is forced to turn off because the return water temperature at the heat pump condenser side (Tw7) is increasing over its maximum threshold. The physical explanation, described in detail in Section 3.5, is that the actual performance of the desiccant wheel is lower than expected, leading to a higher air outlet temperature of the wheel and requiring a larger cooling effect of the heat pump. Therefore, more heat is rejected at the condenser through coils B2 and B3. Moreover, when the outdoor air temperature increases above a maximum value, the heat exchanged at coil B3 decreases and the water temperature in the cooling loop of the heat pump condenser rises. The heat pumps cannot work with such elevated temperatures at the condenser and thus, for safety, turns off. The cooling water cools down during the off period, until the heat pump can restart, giving origin to on/ off cycling.

Fig. 12 shows a relative dry day (x2=10 g/ kg), so dehumidification is not required. The supply air temperature is well controlled around the set-point temperature $\left(22^{\circ} \mathrm{C}\right)$ although the nonmodulating heat pump is cycling as confirmed by the PER trend which oscillates between 0.5 and 1.5 during the daytime. The physical explanation is that the cooling load is in between minimum and maximum cooling capacities of the non-modulating heat pump, forcing the second compressor to turn on and off. Lastly, on this day it can be seen the activation of the anti-stagnation mode around the hour 4574 as proofed by the sharp increase of the regeneration air (Ta11), used as heat rejection media, up to around $65^{\circ} \mathrm{C}$. This is a consequence of the selected DEC configuration, which does not allow to use solar heat for air sensible cooling since a humidifier for direct evaporative cooling of the process air is not present. Thus, solar heat is accumulated until the temperature in the storage reaches the maximum threshold and the antistagnation mode is activated. It can be observed that the PER decreases during anti-stagnation mode. However, the overall impact on PER during the day is relatively small.

The last Figure of this Section (Fig. 13) reports a day characterized by an unintended behaviour linked to an alarm state of the 


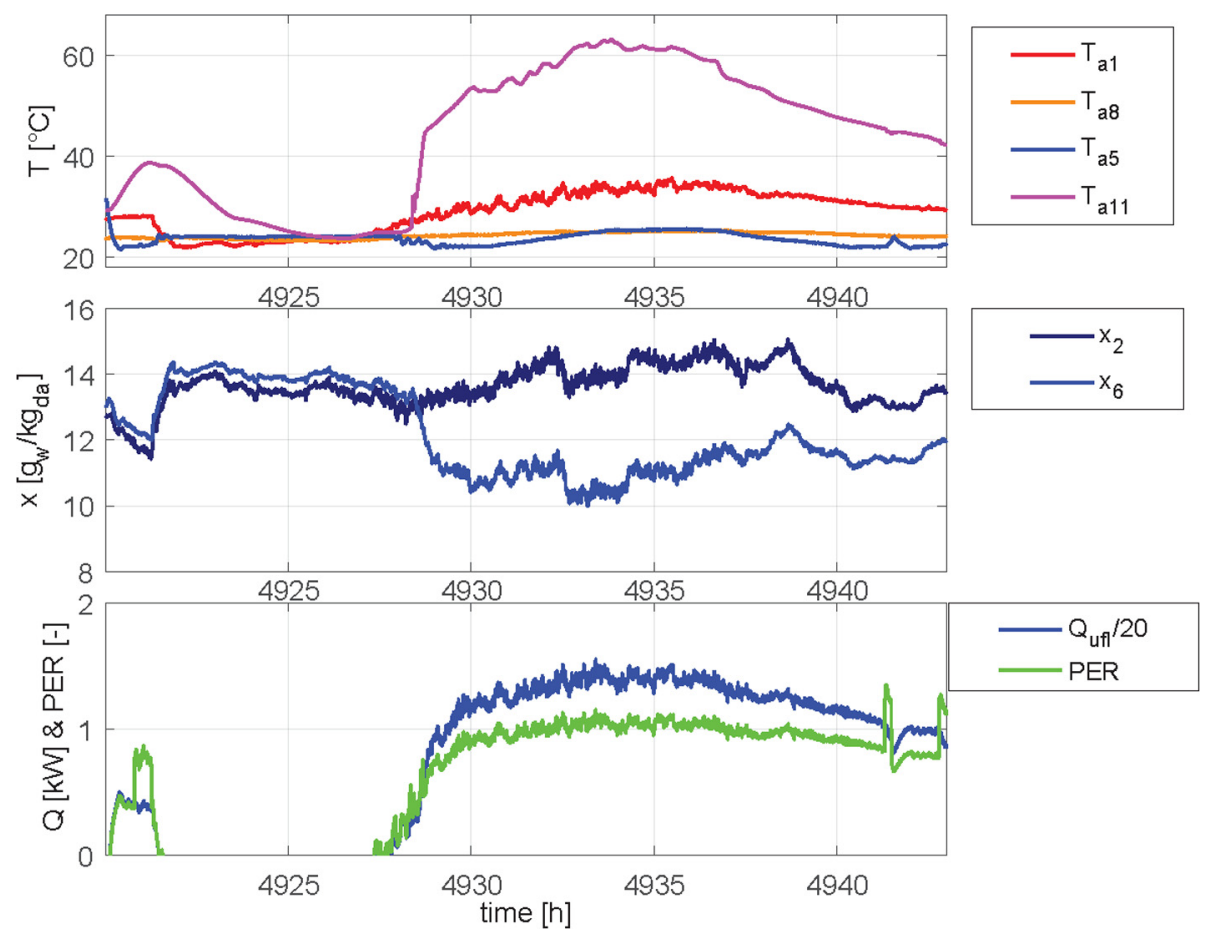

Fig. 10. 25th of July - DH + HP steady.

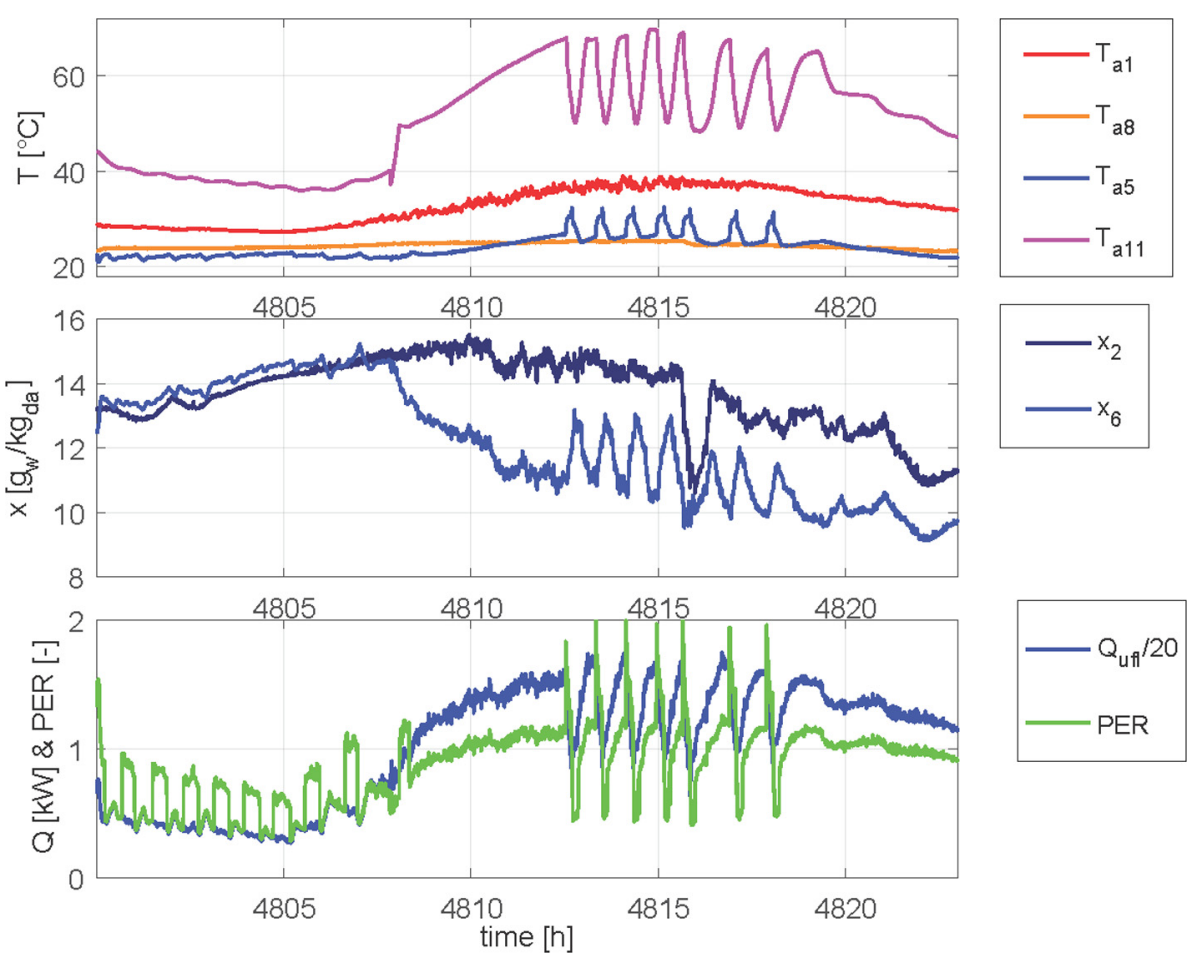

Fig. 11. 20th of July - DH + HP cycling.

heat pump. It is interesting to notice that the system is able to dehumidify the air from 14 to $10 \mathrm{~g} / \mathrm{kg}$ during the daytime. However, the supply air temperature cannot be controlled in this case. It occurs that its value, being lower than the outdoor air temperature, is acceptable for ventilation. The physical reason is that the cooling capacity of the indirect evaporative cooler is sufficient to balance the heat gained during the dehumidification process in the desiccant wheel, but not enough to provide also sensible cooling to the process air. Anyway, the PER of the system is still worth (around 1 during warmest hour) even if the useful cooling and dehumidification power is half that of the first three cases (around $15 \mathrm{~kW}$ during warmest hour). 


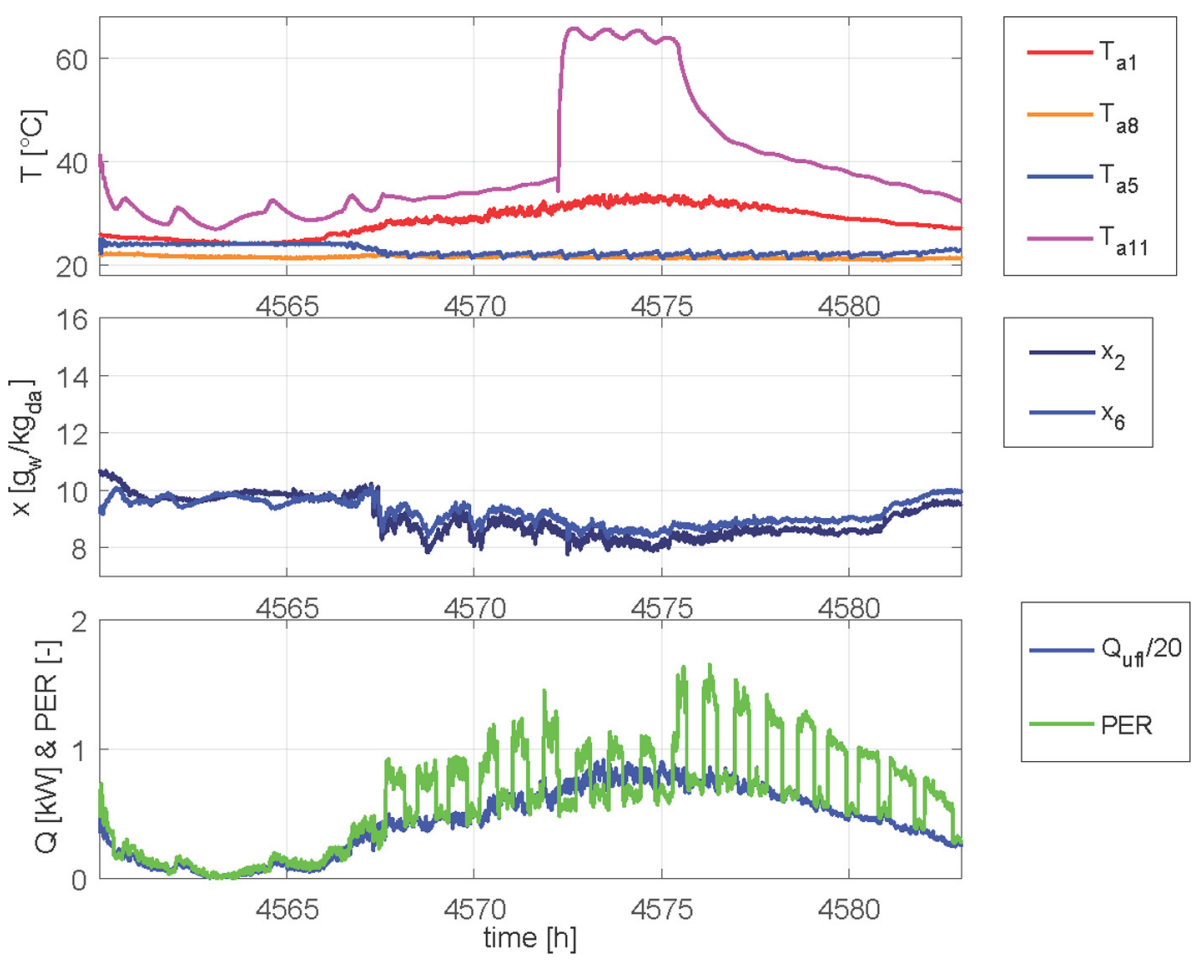

Fig. 12. 10th of July - AC.
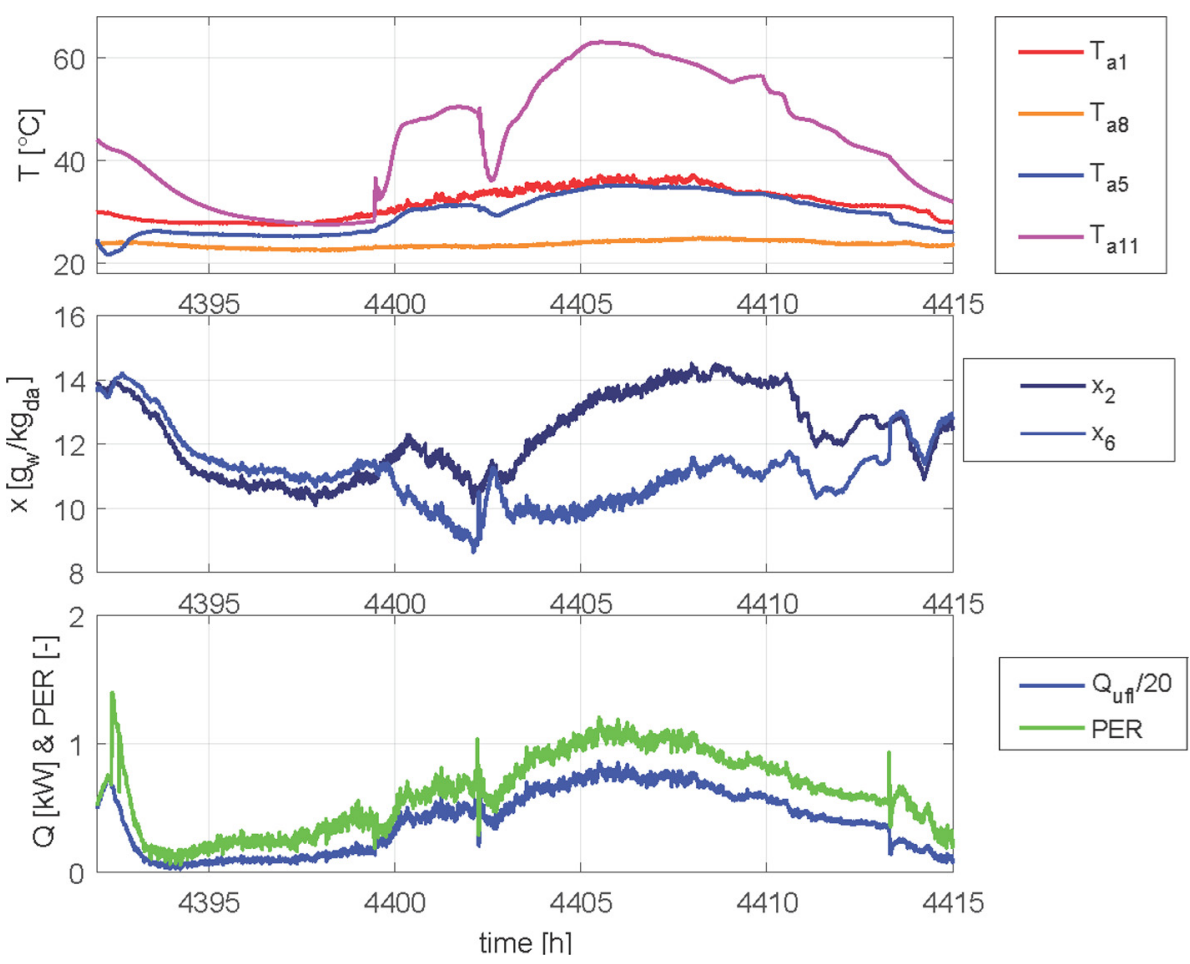

Fig. 13. 3rd of July - DH (HP off).

\subsection{Summary and comparison to a reference system}

In this Section a summary of the previous analysis and a comparison with a reference system are presented. The reference system (Fig. 14) is composed of two fans, a cross-flow heat recovery, a cooling coil (for sensible cooling and dehumidification), and a heating coil. The cooling coil is fed by an electric air-source heat pump (AS-HP), while the heating coil is fed by a natural gas boiler (BLR).

The performance of the reference system has been assessed through a numerical model developed and implemented in a Matlab code. The cross-flow heat exchanger effectiveness has been fixed at 0.6. The gas natural boiler has been modelled considering an overall constant thermal efficiency of 0.9 with respect to the 


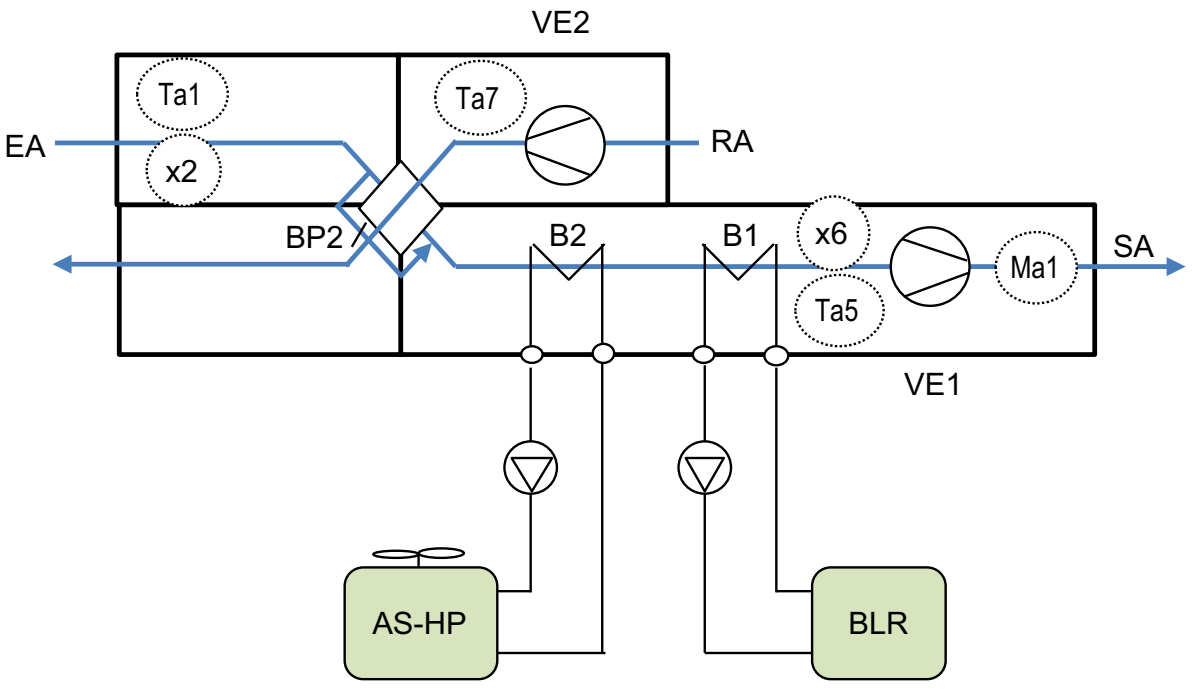

Fig. 14. Reference system.

natural gas gross calorific value and a fixed electric power consumption $(150 \mathrm{~W})$. Lastly, the electric air-source heat pump has been modelled as a black-box mathematical model, starting from the performance data provided by a manufacturer. The inputs are the forward temperature of the working fluid to the AHU cooling coil and the temperature of the external air. The forward temperature of the working fluid to the AHU cooling coil has been assessed starting from the cooling coil apparatus dew point, linked to the set-point humidity by mass of the supply air and to the cooling coil air bypass factor, which has been fixed at 0.15 . The main output of the heat pump model is the energy efficiency ratio $\mathrm{COP}_{\mathrm{e}, \mathrm{AS}-\mathrm{HP}}$ (Fig. 15 ), which is predicted using a polynomial equation. The model is valid only in the temperatures range of Fig. 15.

The model is applied to obtain the same supply condition than the real case using the ambient and return air condition listed in Table 5. Table 6 summarizes some performance figures of the system under analysis. In the first three reported cases (c.n. 1-3) the system is cooling and dehumidifying the external air from 25.9 to $30.6 \mathrm{~kW}\left(\mathrm{Q}_{\mathrm{ufl}}\right)$. The higher values are due to higher temperature and humidity by mass of the external air. The overall electric coefficient of performance of the installed system ( $\left.\mathrm{COP}_{\mathrm{e}, \mathrm{SDEC}}\right)$ ranges between 2.59 and 2.86 while the primary energy ratio (PER) between 1.04 and 1.14. So, the system works better for higher external air temperature and humidity ratio mainly thanks to a

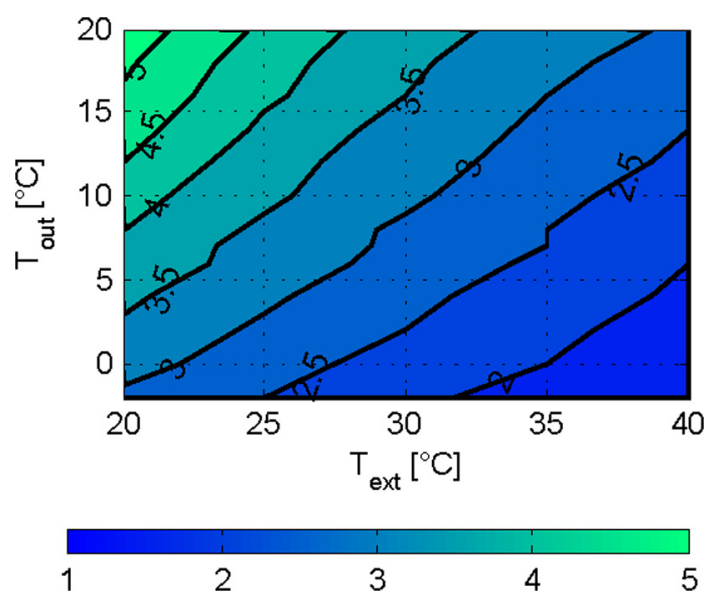

Fig. 15. $\mathrm{COP}_{\mathrm{e}, \mathrm{AS}-\mathrm{HP}}$ air-source electric heat pump. higher heat exchange in the indirect evaporative cooling stage while the electric power consumptions are pretty constants. Moreover, also the primary energy ratio of the previously described reference system is reported $\left(\mathrm{PER}_{\mathrm{ref}}\right)$ in Table 6 . In the first three cases

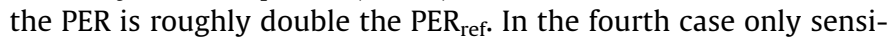
ble cooling is requested, so the desiccant wheel is off and the dif-

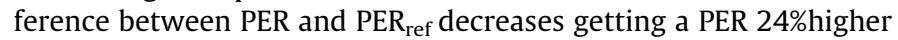

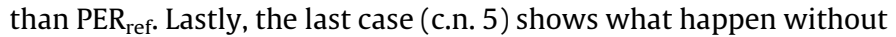
the use of the electric heat pump for post-cooling. The dif-ference between PER and PER ref is the highest, but the $Q_{u f l}$ is just $15.2 \mathrm{~kW}$ although the external air temperature is really high. Thus, the system is exploiting its best performance among the cases under analysis but it is not able to guarantee the supply air set-point conditions.

\subsection{Comparison to expected performances}

A continuous monitoring methodology has been applied to three subsystems, solar, HP and desiccant wheel for the summer 2014 [16]. It shows that the solar plant and the heat pump systems perform as expected whereas the desiccant wheel has discrepancy respect to the expected behaviour. The performance evaluation for partial load behaviour is critical due to the measurement uncertainty on the air side. Thus, it has been chosen to present and compare monitoring results for high cooling load where the uncertainty of the measurements is minimized. In this Section, the c.n. 1-3 presented above are compared to the expected results. The steady state model, presented above, is not suitable to cycling conditions as c.n. 4, so no further analysis is done for this specific day. The inputs of the model are the average values during a period of 10 min of the warmest period for each three days listed in Table 5. The return temperature, Ta7, is strongly higher than expected design temperature thus it reduces the effect of the pas-sive cooling and reduce the expected PER. The comparison focuses on the power exchanged and the performance indicator for each component, as shown in Table 7. The model is applied to obtain the same supply condition as the real case while maintaining the same ambient and return air conditions. The first step consists in calculating the regeneration temperature necessary to dehumidify the air from ambient humidity to the supply humidity according to the theoretical performance of the desiccant wheel. The analysis reveals that, for the same latent heat, the real regeneration temperature is higher by $5-10{ }^{\circ} \mathrm{C}$. This higher regeneration temperature 
Table 5

Input conditions summary.

\begin{tabular}{|c|c|c|c|c|c|c|c|c|c|c|c|}
\hline c.n. & $\mathrm{y}$ & $\mathrm{m}$ & d & $\mathrm{hr}$ & $\Delta t[\mathrm{~min}]$ & Ta1 $\left[{ }^{\circ} \mathrm{C}\right]$ & $\mathrm{x} 2[\mathrm{~g} / \mathrm{kg}]$ & Ta5 $\left[{ }^{\circ} \mathrm{C}\right]$ & x6 [g/kg] & $\operatorname{Ta} 7\left[{ }^{\circ} \mathrm{C}\right]$ & $\operatorname{Ta} 8\left[{ }^{\circ} \mathrm{C}\right]$ \\
\hline 1 & 15 & 7 & 1 & 4363 & 10 & 31.9 & 11.7 & 22.0 & 9.5 & 30.5 & 22.8 \\
\hline 2 & 15 & 7 & 25 & 4936 & 10 & 34.2 & 14.5 & 25.4 & 11.3 & 32.8 & 25.1 \\
\hline 3 & 15 & 7 & 20 & 4812 & 10 & 35.9 & 14.9 & 26.3 & 11.3 & 33.3 & 25.2 \\
\hline 4 & 15 & 7 & 10 & 4575 & 200 & 31.5 & 8.5 & 22.0 & 8.8 & 31.0 & 21.4 \\
\hline 5 & 15 & 7 & 3 & 4406 & 10 & 36.1 & 13.5 & 35.0 & 10.2 & 32.6 & 24.3 \\
\hline
\end{tabular}

Table 6

Outputs summary.

\begin{tabular}{|c|c|c|c|c|c|c|}
\hline c.n. & mode & $\mathrm{Q}_{\mathrm{ufl}}[\mathrm{kW}]$ & Qa_B1 [kW] & $\mathrm{COP}_{\mathrm{e}, \mathrm{SDEC}}[-]$ & PER [-] & $\mathrm{PER}_{\mathrm{ref}}[-]$ \\
\hline 1 & $\mathrm{AC}+\mathrm{DH}$ & 25.9 & -16.1 & 2.59 & 1.04 & 0.53 \\
\hline 2 & $\mathrm{AC}+\mathrm{DH}$ & 28.0 & -17.1 & 2.64 & 1.05 & 0.51 \\
\hline 3 & $\mathrm{AC}+\mathrm{DH}$ & 30.6 & -17.7 & 2.86 & 1.14 & 0.50 \\
\hline 4 & AC & 14.3 & -8.3 & 2.56 & 1.02 & 0.82 \\
\hline 5 & $\mathrm{IEC}+\mathrm{DH}$ & 15.2 & 0 & 2.74 & 1.09 & 0.19 \\
\hline
\end{tabular}

Table 7

Result summary.

\begin{tabular}{|c|c|c|c|c|c|c|c|}
\hline & & \multicolumn{2}{|l|}{ c.n. 1} & \multicolumn{2}{|l|}{ c.n. 2} & \multicolumn{2}{|l|}{ c.n. 3} \\
\hline & & Design & Real & Design & Real & Design & Real \\
\hline Treg DW & {$\left[{ }^{\circ} \mathrm{C}\right]$} & 46.0 & 50.9 & 53.0 & 59.9 & 56.5 & 66.4 \\
\hline Tout DW & {$\left[{ }^{\circ} \mathrm{C}\right]$} & 39.3 & 42.4 & 44.5 & 49.9 & 47.4 & 53.1 \\
\hline $\mathrm{Q}_{\mathrm{s}} \mathrm{DW}$ & {$\left[\mathrm{kW}_{\mathrm{th}}\right]$} & 12 & 17.3 & 17 & 25.5 & 19 & 27.8 \\
\hline $\mathrm{Q}_{\text {lat }} \mathrm{DW}$ & {$\left[\mathrm{kW}_{\mathrm{th}}\right]$} & -9.2 & -9.2 & -13 & -13.2 & -14.6 & -14.5 \\
\hline $\mathrm{Q}_{\text {tot }} \mathrm{DW}$ & {$\left[\mathrm{kW}_{\mathrm{th}}\right]$} & 3.0 & 8.2 & 3.8 & 12.3 & 4.1 & 13.4 \\
\hline $\mathrm{Q}_{\mathrm{s}} \mathrm{HX}$ & {$\left[\mathrm{kW}_{\mathrm{th}}\right]$} & -19.9 & -18.0 & -23.2 & -23.3 & -26.4 & -26.4 \\
\hline$\eta_{\mathrm{T}} \mathrm{HX}$ & {$[-]$} & $72 \%$ & $55 \%$ & $72 \%$ & $57 \%$ & $72 \%$ & $57 \%$ \\
\hline $\mathrm{Q}_{\mathrm{S}} \mathrm{B} 1$ & {$\left[\mathrm{~kW}_{\mathrm{th}}\right]$} & -9.2 & -16.1 & -8.7 & -17.1 & -8.7 & -17.7 \\
\hline $\mathrm{T}_{\text {out }}$ cond & {$\left[{ }^{\circ} \mathrm{C}\right]$} & 38.4 & - & 41.3 & - & 43.3 & - \\
\hline $\mathrm{T}_{\text {in }}$ cond & {$\left[{ }^{\circ} \mathrm{C}\right]$} & 33.6 & 38.6 & 36.7 & 41.9 & 39.3 & 43.0 \\
\hline $\mathrm{T}_{\text {out }}$ eva & {$\left[{ }^{\circ} \mathrm{C}\right]$} & 20.3 & 15.9 & 23.8 & 20.9 & 24.7 & 21.7 \\
\hline $\mathrm{Q}_{\mathrm{el}} \mathrm{HP}$ & {$\left[\mathrm{kW}_{\mathrm{el}}\right]$} & 1.9 & 3.9 & 1.9 & 4.3 & 2.1 & 4.4 \\
\hline $\mathrm{COP}_{\mathrm{e}, \mathrm{WW}-\mathrm{HP}}$ & {$[-]$} & 4.7 & 4.1 & 4.5 & 4.0 & 4.2 & 4.1 \\
\hline$Q_{s}$ B2 & {$\left[\mathrm{kW}_{\mathrm{th}}\right]$} & 3.0 & 7.5 & 1.8 & 5.5 & 1.7 & 4.5 \\
\hline $\mathrm{Q}_{\mathrm{s}} \mathrm{B} 3$ & {$\left[\mathrm{~kW}_{\mathrm{th}}\right]$} & 7.8 & 14.2 & 8.6 & 16.5 & 8.9 & 15.5 \\
\hline $\mathrm{Q}_{\mathrm{s}} \mathrm{B} 4$ & {$\left[\mathrm{~kW}_{\mathrm{th}}\right]$} & 14.1 & 14.8 & 20.6 & 22.1 & 23.2 & 30.7 \\
\hline SF reg & {$[-]$} & $64 \%$ & $52 \%$ & $70 \%$ & $58 \%$ & $72 \%$ & $66 \%$ \\
\hline$P_{\text {tot }}$ & {$\left[\mathrm{kW}_{\mathrm{el}}\right]$} & 8.5 & 10.0 & 8.4 & 10.7 & 8.6 & 10.8 \\
\hline $\mathrm{Q}_{\mathrm{ufl}}$ & {$\left[\mathrm{kW}_{\mathrm{th}}\right]$} & 26.1 & 25.9 & 28.1 & 28.0 & 31.0 & 30.6 \\
\hline PER & {$[-]$} & 1.23 & $1.04 \pm 0.07$ & 1.33 & $1.05 \pm 0.08$ & 1.44 & $1.14 \pm 0.10$ \\
\hline
\end{tabular}

leads to a higher temperature out stream of the desiccant wheel that strongly reduces the efficiency of the wheel. In fact, the overall enthalpy difference over the wheel is increased by approximatively 4 times for the first three days. The extra energy gain through the desiccant wheel has to be rejected through passive cooling (Static Heat exchanger) and active cooling (Water/Water heat pump). The cooling effect through the air/air heat exchanger is coherent with the expected value. Nevertheless, these similar values are due to higher inlet temperature on the hot side of the heat exchanger, in fact the temperature efficiency of the static heat exchanger is lower than expected, around 55\% instead of $72 \%$ expected from the manufacturer's data sheet. Due to the aforementioned performances drops, the cooling power requested from coil B1 is higher. Thus, the running time and the electrical power of the heat pump increase. Moreover, the rejected heat on the condensation side increases, that leads to higher temperature on the condensation loop thus slightly reducing the $\mathrm{COP}_{\mathrm{e}, \mathrm{WW} \text {-HP }}$ of the heat pump. Nevertheless, the continuous monitoring methodology applied to heat pump sub-system confirms that the heat pump is performing as expected [16]. For these three days, due to the discrepancy between the real performance and the expected performance of the desiccant wheel and the static heat exchanger, the perfor-mance indicator of the overall system, PER, is reduced between
0.30 and 0.19 respected to the design expected performance, i.e. a PER approximately 20\% lower than expected. In these three specific cases the PER uncertainty is less than 0.1 .

\section{Applied improvements}

During the first operation period, a continuous commissioning activity allowed the detection of control strategy errors and components failures. In the following, a brief description of principal applied improvements and the related results is presented.

\subsection{Heat pump}

As mentioned before, when in summer operation the supply air temperature becomes too high, the plant control logic requires the intervention of the cooling coil. This cooling coil is powered by the evaporator loop of the electric reversible heat pump. The two vapour compressors are activated through an internal on/off control logic, thus the machine modulates only at $0-50-100 \%$ of the nominal capacity. The final effect of this 3 step capacity control is a uselessly low temperature at the evaporator side. For this reason, an external function was developed to force the stop of the compressors until a certain water temperature is reached, exploit- 
ing the plant inertia with a puffer on each side of the heat pump. The increasing of the evaporator temperature raises the $\mathrm{COP}_{e}, \mathrm{ww}$ HP of the machine, thus the PER of the whole plant. Furthermore, the forcing function decreases the number of on/off cycles. The comparison procedure is not simple. This plant is not in a test laboratory, thus it is not possible to run the plant in a sort of "test mode". Thus, the 30th of August 2013 and the 23rd of July 2014 have been selected (Table 8 ) as similar days before and after the heat pump optimization.

Fig. 16 shows the heat pump behaviour during two hours of operation, before and after the application of the described optimization measure. During the analysed days, the evaporator fluid average temperature raises from $15.6{ }^{\circ} \mathrm{C}$ to $17.5^{\circ} \mathrm{C}$, and the average $\mathrm{COP}_{\mathrm{e}, \mathrm{WW} \text {-HP }}$ raises from 4.11 to 4.65 , despite the average ambient temperature and the average return air temperature after the heat exchanger (condenser sinks) are higher for the second case. Even if in the analysed days the heat pump operation is similar, the different air temperatures prevent a proper quantitative evaluation of the optimization effects. However, it is possible to assess that the global performance is sensibly improved, since the performance figure is higher after optimization despite a higher condenser temperature $\left(+1.5^{\circ} \mathrm{C}\right)$.

\subsection{Air-to-air heat exchanger}

When the temperature difference between the air inlet streams (Ta3 - Ta8) is low, it is not immediate to state if the use of the static heat exchanger is convenient. The heat exchanger allows sensible heat exchange with the return airstream. This produces energy savings both in winter and in summer (Indirect Evaporative Cooling), as the temperature gap on the supply air coil B1 is lower. Considering the airflow $\left(5000 \mathrm{~m}^{3} / \mathrm{h}\right)$, each Celsius degree for Ta4 represents about $2 \mathrm{~kW}$ of thermal power to the coil B1. However, the heat exchanger produces an extra pressure drop for the VE1 fan, causing an increase of its electrical power consumption. Assuming BP1 open, when BP2 is closed and the airstream crosses the heat exchanger, the VE1 electrical power is about $1600 \mathrm{~W}$. When BP2 is open, the electrical power falls around $1000 \mathrm{~W}$, with a saving of 600 $\mathrm{W}$ electric. Considering a $\mathrm{COP}_{\mathrm{e}, \mathrm{ww}-\mathrm{HP}}$ of 4 for the heat pump and the value of $2.4 \mathrm{~kW}$ th $/{ }^{\circ} \mathrm{C}$ for $\mathrm{B} 1$ coil, it is straightfor-ward that the temperature difference that balances electrical power consumptions is $1.2^{\circ} \mathrm{C}$. In this specific case, taking into account possible measurement errors, the heat exchanger is bypassed if the temperature difference is lower than $1.5^{\circ} \mathrm{C}$.

\subsection{Desiccant rotor}

The initial rotation speed was $24 \mathrm{RPH}$. During summer 2015, some tests allowed the evaluation of the wheel performance related to speed changes from $24 \mathrm{RPH}$ to $12 \mathrm{RPH}$ and $18 \mathrm{RPH}$. In Fig. 17, graph on the left shows latent daily heat transfer [kWh], while the graph on the right sensible daily heat transfer [kWh].

As the rotational speed decreases, dehumidification capacity decreases and consequently sensible heating decreases. To investigate further this latter aspect, it is interesting to calculate the enthalpy change of the wheel for different rotational speed values. For an adiabatic dehumidification process, the enthalpy difference of the process air is zero, i.e. sensible energy supplied to the
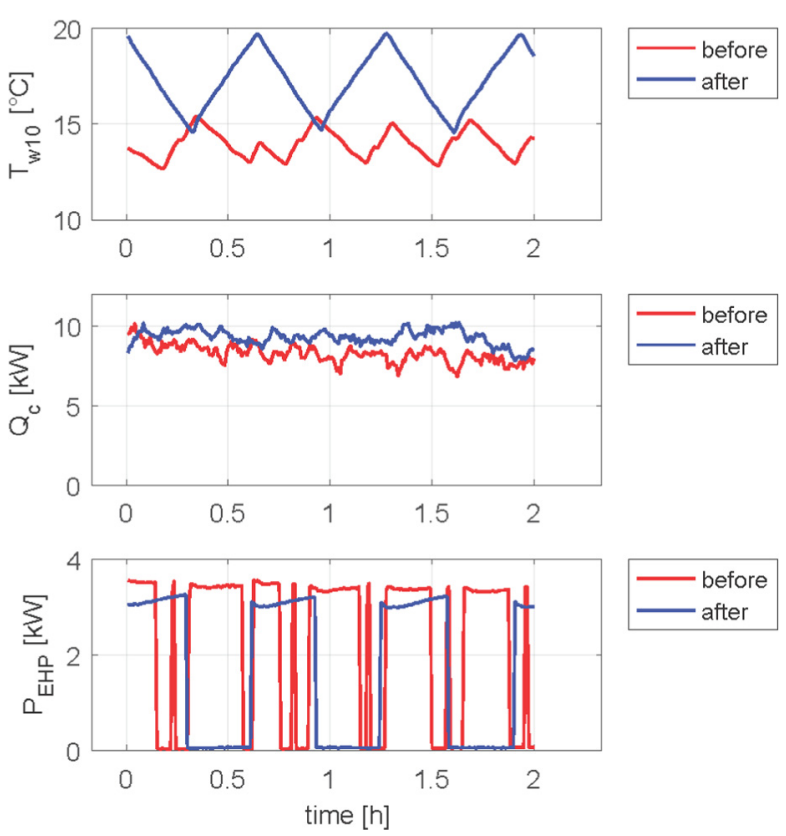

Fig. 16. Detailed heat pump behaviour, before (30/08/2013) and after (23/07/2014) the control optimization.

process air is equal to the removed latent energy. In real applications, sensible energy supplied to the process air is always higher than the removed latent energy, due to both the heat of wetting released during adsorption and the sensible heat transferred from the regeneration section to the dehumidification section of the wheel. This results in an overheating of the process air, which is detrimental for the overall system performance. The aim of the Fig. 18 is to evaluate the overheating in the real case with respect to the overheating based on the wheel performance provided by the manufacturer, and to evaluate the effect of rotational speed.

As the rotational speed decreases, the overheat slightly decreases. Therefore, it is concluded that with a low rotational speed the overheating problem can be reduced but it is necessary to note that the low impact of this change is within the measurement uncertainty range.

\subsection{AHU filters}

Electrical power of AHU was very sensitive to the obstruction of the air filters. If maintenance procedures are not well scheduled, filters could accumulate dust particles more quickly than expected. An excessive obstruction of the filters causes very high pressure drops, which in turn cause an increase of the fans electrical consumption when a constant airflow rate has to be maintained.

Fig. 19 shows the daily average electrical power of fans. It is interesting to note the gap of electrical power trend in 25/04, about $2 \mathrm{~kW}$ in free cooling mode due to filters replacement. During four months of operation, the average electrical power increased by 2 $\mathrm{kW}$. Considering the overall electrical power consumption in nominal conditions ( $8 \mathrm{~kW}$, see Section 2 ), the filters have an impact of about $25 \%$ on the electrical effectiveness of the plant. This Section highlights that simple maintenance operation could be more

Table 8

Reference days for the heat pump optimization check.

\begin{tabular}{|c|c|c|c|c|c|}
\hline Date & Cooling energy $\left[\mathrm{kWh}_{\mathrm{th}}\right]$ & Electrical energy $\left[\mathrm{kWh}_{\mathrm{el}}\right]$ & Water $\mathrm{T}$ (average) $\left[{ }^{\circ} \mathrm{C}\right]$ & Ambient $\mathrm{T}$ (average) $\left[{ }^{\circ} \mathrm{C}\right]$ & Return air $\mathrm{T}$ after $\mathrm{HX}\left[{ }^{\circ} \mathrm{C}\right]$ \\
\hline $30 / 08 / 2013$ & 240 & 58.2 & 15.6 & 24.8 & 28.8 \\
\hline $23 / 07 / 2014$ & 231 & 49.7 & 17.5 & 26.8 & 31.5 \\
\hline
\end{tabular}



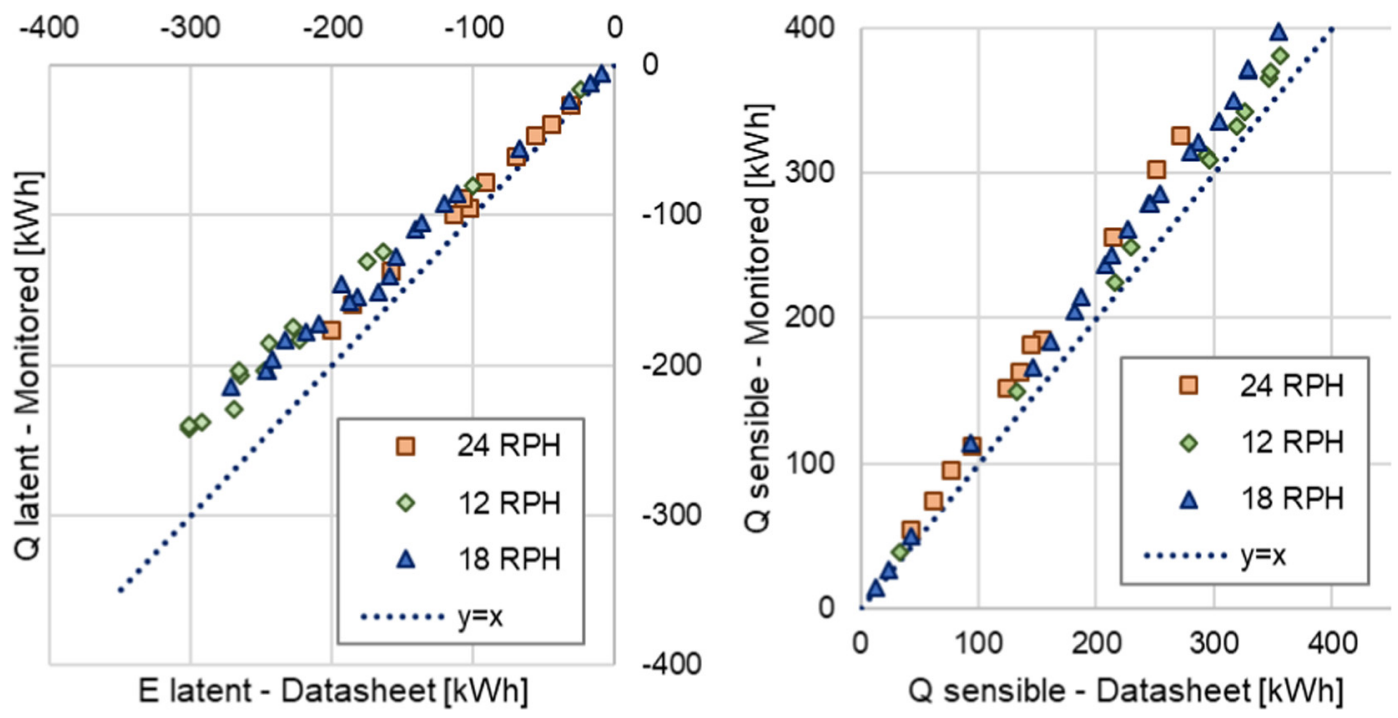

Fig. 17. Desiccant wheel latent and sensible heat transfer - comparison between monitored and manufacturer performance data.

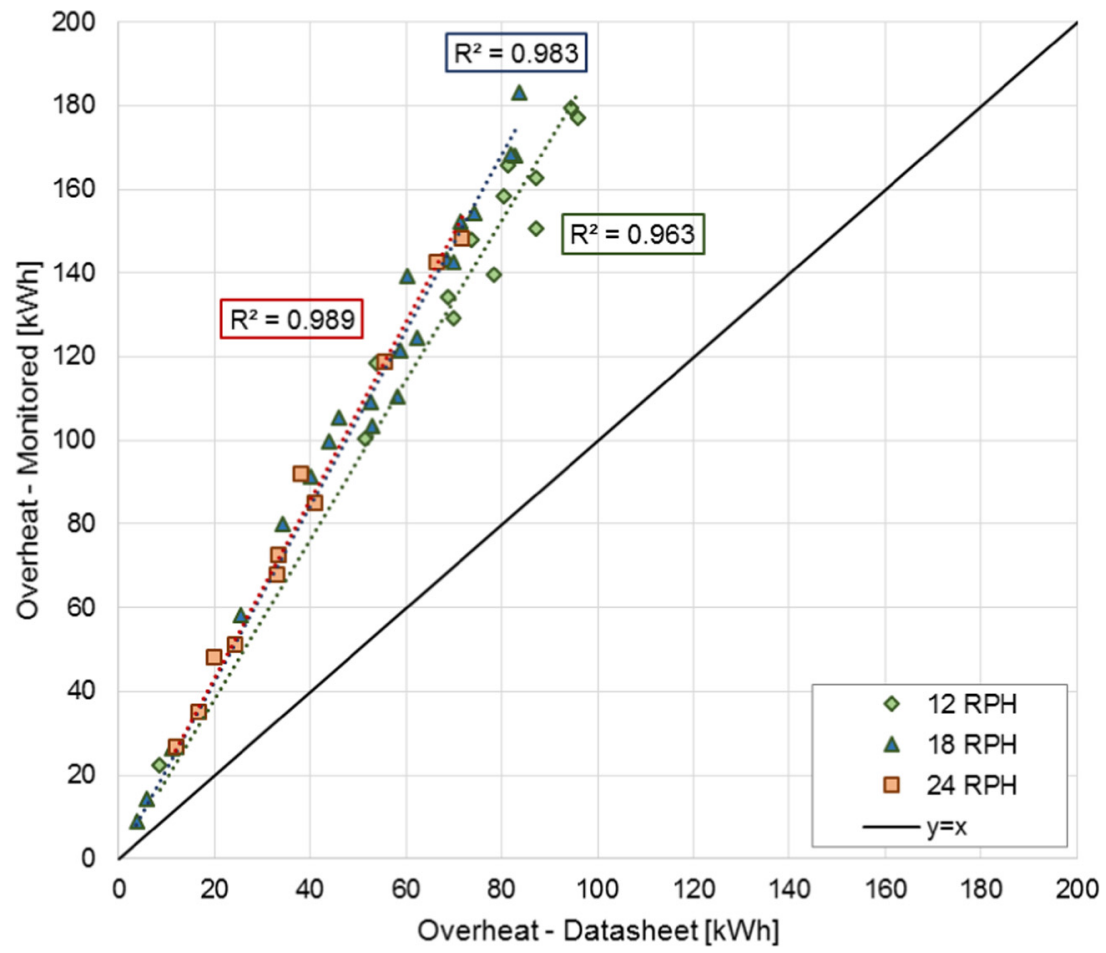

Fig. 18. Desiccant wheel overheat - comparison between monitored data and manufacturer performance data.

effective than sophisticated optimization measures. Thus, the schedule of maintenance procedures is crucial to achieve expected performances, especially for complex systems.

\section{Conclusions}

A solar driven desiccant evaporative cooling air-conditioning system coupled with a vapour compression heat pump has been presented and analysed. Due to the high number of system components, the system has several operating modes. For this reason, an ad hoc control strategy aiming at guaranteeing supply air temperature and humidity set-points, smooth transition between operating modes and safety operation (antifreeze, anti-stagnation, etc.) has been implemented. The system has been installed at a student dormitory in Milan and monitored for more than two years. The analysis of some characteristic summer days of July 2015 shows that overall performances exceed those of a conventional reference system. Specifically, in the cooling and dehumidification operation mode, the primary energy ratio of the system (PER) is roughly double. On the other hand, the performances are lower than those expected during the design phase by about $20 \%$. The main reason is the underperformance of the desiccant wheel, as also pointed out in the work of Frein et al. [16] through a continuous commissioning methodology applied on this specific system. The heat pump control logic has been optimized, allowing a reduction in on/off cycling and a $\mathrm{COP}_{\mathrm{e}, \mathrm{ww} \text {-HP }}$ improvement thanks to higher evaporator temperatures. The heat exchanger bypass control has 


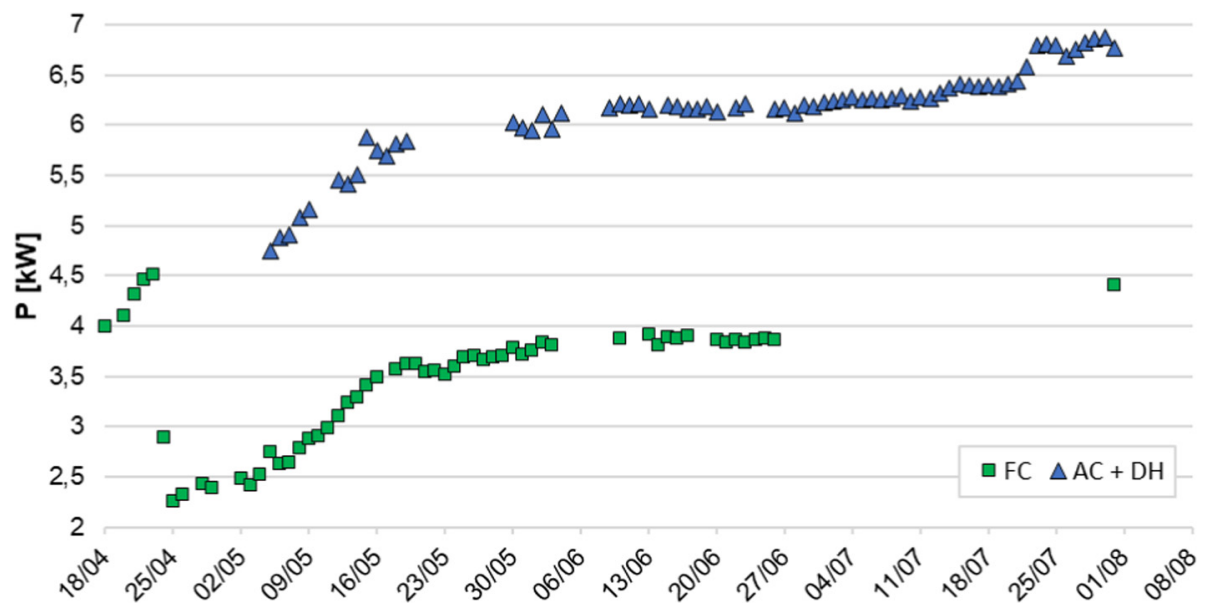

Fig. 19. Fans electrical power.

been changed taking into account extra pressure drops for supply stream fan, opening the bypass when extra costs on the fan balance thermal benefits on heat exchanger. The wheel revolution speed has been optimized, as high measurement uncertainties and lack of standard certification represent main limits of the analysis. Lastly, the extra electric power of the fans due to the increasing obstruction of the air filters has been quantified as $25 \%$ of the overall system electric power consumption in four months of continuous operation.

\section{References}

[1] K. Daou, R. Wang, Z. Xia, Desiccant cooling air conditioning: a review, Renew. Sustain. Energy Rev. 10 (2006) 55-77, https://doi.org/10.1016/j. rser.2004.09.010.

[2] T.S. Ge, Y. Li, R.Z. Wang, Y.J. Dai, A review of the mathematical models for predicting rotary desiccant wheel, Renew. Sustain. Energy Rev. 12 (2008) 1485-1528, https://doi.org/10.1016/j.rser.2007.01.012.

[3] L.Z. Zhang, J.L. Niu, Performance comparisons of desiccant wheels for air dehumidification and enthalpy recovery, Appl. Therm. Eng. 22 (2002) 13471367, https://doi.org/10.1016/S1359-4311(02)00050-9.

[4] P. Stabat, D. Marchio, Heat and mass transfer modeling in rotary desiccant dehumidifiers, Appl. Energy. 86 (2009) 762-771, https://doi.org/10.1016/j. apenergy.2007.06.018.

[5] C.R. Ruivo, A. Carrillo-Andrés, J.J. Costa, F. Domínguez-Muñoz, A new approach to the effectiveness method for the simulation of desiccant wheels with variable inlet states and airflows rates, Appl. Therm. Eng. 58 (2013) 670-678, https://doi.org/10.1016/j.applthermaleng.2011.12.052.

[6] M. Aprile, M. Motta, Grey-box modelling and in situ experimental identification of desiccant rotors, Appl. Therm. Eng. 51 (2013) 55-64, https://doi.org/10.1016 j.applthermaleng.2012.08.065.

[7] P. Bourdoukan, E. Wurtz, P. Joubert, Experimental investigation of a solar desiccant cooling installation, Sol. Energy. 83 (2009) 2059-2073, https://doi. org/10.1016/j.solener.2009.08.005.
[8] D. La, Y.J. Dai, Y. Li, R.Z. Wang, T.S. Ge, Technical development of rotary desiccant dehumidification and air conditioning: a review, Renew. Sustain. Energy Rev. 14 (2010) 130-147, https://doi.org/10.1016/j.rser.2009.07.016.

[9] T.S. Ge, F. Ziegler, R.Z. Wang, H. Wang, Performance comparison between a solar driven rotary desiccant cooling system and conventional vapor compression system (performance study of desiccant cooling), Appl. Therm. Eng. $\quad 30 \quad$ (2010) 724-731, https://doi.org/10.1016/j. applthermaleng.2009.12.002.

[10] H.-M. Henning, Solar assisted air conditioning of buildings - an overview, Appl. Therm. Eng. 27 (2007) 1734-1749, https://doi.org/10.1016/j. applthermaleng.2006.07.021.

[11] H.M. Henning, T. Pagano, S. Mola, E. Wiemken, Micro tri-generation system for indoor air conditioning in the Mediterranean climate, Appl. Therm. Eng. 27 (2007) 2188-2194, https://doi.org/10.1016/j.applthermaleng.2005.07.031. P.

[12] Mazzei, F. Minichiello, D. Palma, HVAC dehumidification systems for thermal comfort: a critical review, Appl. Therm. Eng. 25 (2005) 677-707, https:// doi.org/10.1016/j.applthermaleng.2004.07.014.

[13] M. Beccali, P. Finocchiaro, B. Nocke, Energy and economic assessment of desiccant cooling systems coupled with single glazed air and hybrid PV/ thermal solar collectors for applications in hot and humid climate, Sol. Energy. 83 (2009) 1828-1846, https://doi.org/10.1016/j.solener.2009.06.015.

[14] M. Beccali, P. Finocchiaro, B. Nocke, Energy performance evaluation of a demo solar desiccant cooling system with heat recovery for the regeneration of the adsorption material, Renew. Energy. 44 (2012) 40-52, https://doi.org/10.1016/ j.renene.2011.12.021.

[15] M. Aprile, R. Scoccia, M. Motta, Modelling and control optimization of a solar desiccant and evaporative cooling system using an electrical heat pump, Energy Procedia. 30 (2012) 478-489, https://doi.org/10.1016/ j.egypro.2012.11.057.

[16] A. Frein, M. Aprile, M. Muscherà, R. Scoccia, M. Motta, A continuous commissioning analysis and its application to a new installed solar driven DEC system coupled with heat pump, Energy Procedia. 70 (2015) 435-444, https://doi.org/10.1016/j.egypro.2015.02.145.

[17] J. Seem, C. Park, J. House, A new sequencing control strategy for air-handling units, HVAC\&R Res. 5 (1999) (accessed May 30, 2014) http:// www.tandfonline.com/doi/abs/10.1080/10789669.1999.10391222.

[18] T. Vitte, J. Brau, N. Chatagnon, M. Woloszyn, Proposal for a new hybrid control strategy of a solar desiccant evaporative cooling air handling unit, Energy Build. 40 (2008) 896-905, https://doi.org/10.1016/j.enbuild.2007.07.004. 